1

2

3

4

5

6

7

8

12

\title{
Multiple sources of Shh are critical for the generation and scaling of ventral spinal cord oligodendrocyte precursor populations
}

Running Title: Shh sources scale spinal OPC numbers

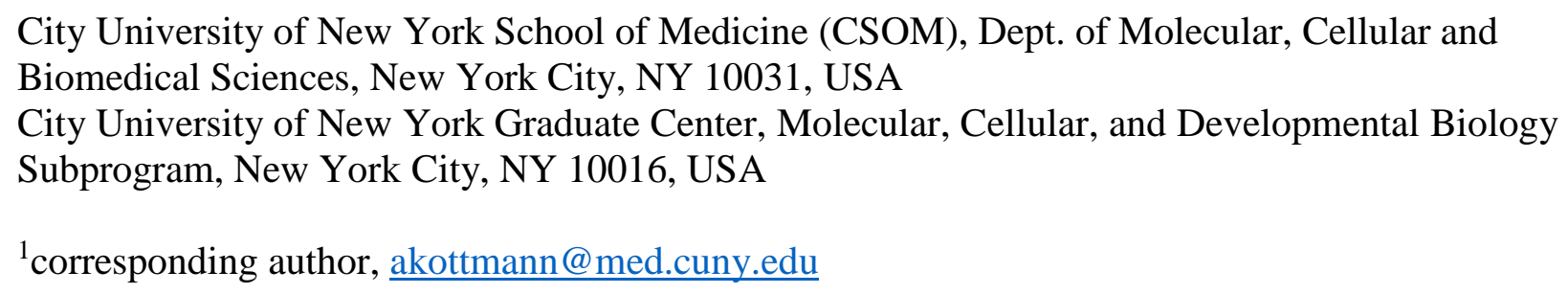

Key Words: sonic hedgehog, scale invariance, motor neurons, oligodendrocyte precursor, spinal cord

\section{Lev Starikov and Andreas H. Kottmann'1} \section{(1)} \section{(1)} 1 \section{6}

0


Abstract:

Graded Sonic Hedgehog (Shh) signaling emanating from notochord and floorplate patterns the early neural tube. Soon thereafter, Shh signaling strength within the ventricular zone becomes dis-contiguous and discontinuous along the ventral to dorsal axis suggesting a distribution of Shh that cannot be achieved by diffusion alone. Here we discover that sequential activation of Shh expression by ventricular zone derivatives is critical for counteracting a precocious exhaustion of the Olig2 precursor cell population of the pMN domain at the end of motor neuron genesis and during the subsequent phase of ventral oligodendrocyte precursor production. Selective expression of Shh by motor neurons of the lateral motor column at the beginning of oligodendrogenesis ensures a more yielding pMN domain at limb levels compared to thoracic levels. Thus, patterned expression of Shh by ventricular zone derivatives including earlier born neurons contributes to the scaling of the spinal cord along the anterior - posterior axis by regulating the activity of a select ventricular zone precursor domain at later stages of development. 
Introduction:

55 The “Bauplan”, or body plan, of vertebrates can be recognized among members of the same

56 species and across phyla despite significant differences in the absolute size of individuals of the

57 same species or the form of different species. Chiefly responsible for our ability to recognize the

58 common features of a body plan is the proportionate differentiation and growth of the constituent

59 parts of an organism irrespective of absolute size. How developmental processes maintain a

60 constant ratio of physical pattern features with changing size, a property known as scale

61 invariance, is not completely understood (Huang and Umulis 2018).

62

63 Successful development is dependent on highly stereotyped series of inductive events that result

64 in the determination of progressively increasing numbers of cell fates within rapidly growing

65 tissues. Ensuring scale invariance could be achieved by mechanisms that are distinct from cell

66 fate determination processes and could act at different developmental stages (Barkai and Ben-Zvi

67 2009, Umulis and Othmer 2013). Alternatively, patterning mechanisms themselves could be

68 modified to generate a size-invariant output (Kicheva and Briscoe 2015). Cell fate determination

69 is governed by a handful of cell signaling factors termed morphogens that are secreted from

70 spatial fix-points in the developing embryo and form gradients of activity across a developmental

71 field (Lander 2007). Morphogen signaling induces distinct transcriptional programs in naïve

72 precursor cells dependent on signaling thresholds that are determined by signal strength and

73 duration (Kicheva, Bollenbach et al. 2014). Experimental and theoretical studies revealed several

74 mechanisms by which morphogen signaling can be scaled to embryo size (Gregor, Bialek et al.

75 2005, Houchmandzadeh, Wieschaus et al. 2005, Howard and ten Wolde 2005, McHale, Rappel

76 et al. 2006, Ben-Zvi and Barkai 2010, Cheung, Miles et al. 2014, Uygur, Young et al. 2016). The 
77 commonality of these studies is that they define mechanisms of scale invariance across embryos

78 during early stages of development. However, scaling occurs within the same embryo and

79 throughout development as different body parts reveal proportionate changes in size regardless

80 of when they are specified during development. How is proportionality ensured across

81 developmental stages within the same embryo?

82

83 We have explored this question in the context of the switch from neurogenesis to gliogenesis in

84 the developing neural tube. The spinal cord is a tube-like structure with enlargements at

85 segmental levels that provide control of, and receive proprioceptive information from, limbs. The

86 larger spinal cord at brachial (forelimb) and lumbar (hindlimb) levels compared to thoracic levels

87 is chiefly the result of the presence of a greater number of motor neurons (MNs) that sub serve

88 limb musculature, and correspondingly larger numbers of interneurons and glial cells (Bjugn and

89 Gundersen 1993, Dasen 2017). Since the basic patterning and structure of the spinal cord is

90 highly similar along the neuraxis, the difference in size between limb levels and thoracic

91 segments allows comparative studies that might reveal mechanisms involved in scale invariance.

92 MNs are among the very first neurons in the developing neural tube whose fate becomes

93 specified while most interneurons and all types of glia develop later (Jessell 2000). Whether and

94 how the earlier production of neurons plays a role in the proportionate differentiation of

95 subsequent cell types is not well understood. MNs and oligodendrocyte precursor cells (OPCs)

96 emerge subsequently from the same domain, the "pMN" domain, within the ventricular zone of

97 the developing spinal tube (Bergles and Richardson 2015, Traiffort, Zakaria et al. 2016)

98 suggesting that cell-autonomous as well as cell non-autonomous mechanisms could be involved

99 in the sequential and proportionate differentiation of MNs and OPCs (Traiffort, Zakaria et al. 
100

101

102

103

104

105

106

107

108

109

110

111

112

113

114

115

116

117

118

119

120

121

122

2016). The elucidation of the molecular control mechanisms that determine the precise "switch" from neurogenesis to gliogenesis of the pMN domain and the segment-specific yield of the pMN domain have been hampered by a scarcity of cell type selective- and temporally- specific genetic tools to dissect MN and OPC production within the pMN domain. Despite these difficulties, studies have implicated the morphogen Sonic Hedgehog (Shh) in regulating both, MN and OPC production (Briscoe and Ericson 1999, Traiffort, Zakaria et al. 2016).

\section{Shh plays a critical role in MN and OPC differentiation at several developmental stages. First,} graded Shh signaling originating from the notochord induces distinct transcriptional programs in overlying naïve neural ectoderm cells in a concentration-dependent manner that leads to the establishment of molecularly distinct precursor domains along the ventral to dorsal axis of the developing neural tube (Dessaud, McMahon et al. 2008, Alaynick, Jessell et al. 2011, Yu, McGlynn et al. 2013),. The transcription factors activated by Shh are responsible for determining the cell fates in the derivatives of these precursor domains. Thus, Olig2 expression marks MN precursors, (pMN) (Mizuguchi, Sugimori et al. 2001, Novitch, Chen et al. 2001), Nkx2.2 expression marks the more ventral V3 interneuron progenitors (p3), and Dbx1 is expressed in the p0 domain located at the equator of the neural tube leading to interneurons situated dorsal to MNs (Briscoe, Pierani et al. 2000). Subsequently, persistent Shh signaling originating from the medial floorplate (MFP) located at the ventral midline of the developing neural tube is critical for maintaining the identities of each of these domains throughout neurogenesis (Dessaud, Ribes et al. 2010). The ventral neural tube expands rapidly during neurogenesis and Shh signaling strength measured by expression levels of Shh target genes declines progressively within the precursor domains (Balaskas, Ribeiro et al. 2012, Kicheva, Bollenbach et al. 2014). Surprisingly, 
123 the beginning of oligodendrogenesis is marked by increased Shh signaling strength within the

124 pMN domain (Danesin, Agius et al. 2006). How this dynamic increase in Shh signaling is

125 achieved subsequently to a decline in Shh signaling strength and whether it is of functional

126 importance for OPC specification and production is an area of active research (Traiffort, Zakaria

127 et al. 2016). Since the Shh gradient emanating from the MFP displays a constant decay length

128 and does not scale with congruent and rapid growth during early development (Cohen, Kicheva

129 et al. 2015), its influence on pMN domain activity must likely wane during neurogenesis.

130 Accordingly, multiple adaptation mechanisms have been proposed to underlie temporally

131 dynamic Shh signaling at the time of initiation of OPC production (Traiffort, Zakaria et al.

132 2016). One such mechanism is the accumulative storage of Shh in the extracellular matrix

133 followed by Sulfatase 1 dependent release leading to a greater concentration of Shh than could

134 be achieved by continuous production and diffusion (Danesin, Agius et al. 2006, Touahri,

135 Escalas et al. 2012, Al Oustah, Danesin et al. 2014). While the genetic ablation of Sulfatase 1

136 curtails the production of OPCs, the current experiments cannot exclude the possibility that other

137 signaling factors than Shh are released from the extracellular matrix by Sulfatase 1 and then

138 participate in the regulation of OPC production. Another mechanism might be the sequential

139 production of Shh by previously specified ventricular zone derivatives (VZD). Prominent

140 sources of VZD ${ }_{\text {Shh }}$ are the lateral floorplate $\left(\mathrm{LFP}_{\mathrm{Shh}}\right)$ (Charrier, Lapointe et al. 2002, Park, Shin et

141 al. 2004, Al Oustah, Danesin et al. 2014), which is constituted by cells emigrating from the p3

142 domain, and MNs (MN $\mathrm{Mhh}_{\text {}}$ (Oppenheim, Homma et al. 1999, Akazawa, Tsuzuki et al. 2004). The

143 selective ablation of Shh from LFP or MNs without impacting earlier patterning of the spinal

144 cord has not been achieved and causal evidence for the involvement of $L F P_{S h h}$ and $\mathrm{MN}_{\text {Shh }}$ in the

145 regulation of OPC generation is therefore lacking. 
146 Here we produced a series of mouse lines with different degrees and tissue selectivity of

147 conditional Shh gene ablation from the MFP, LFP, and MNs during spinal cord development.

148 We find that VZD ${ }_{\text {shh }}$ is critical for the maintenance of the Olig2 expressing cell population in the

149 pMN domain during the phase of oligodendrocyte precursor cell (OPC) production. While early

150 neural tube patterning and MN development can proceed successfully in the absence of these

151 Shh sources, the pMN domain exhausts of Olig2 expressing cells during neurogenesis leading to

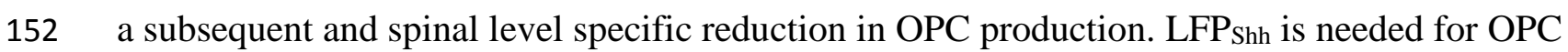

153 production throughout the spinal neuraxis. In contrast, $\mathrm{MN}_{\mathrm{Shh}}$, which occurs earlier at limb levels

154 than thoracic levels, is critical for maintaining a larger pMN domain at limb levels compared to

155 thoracic segments throughout OPC production. Our data provides causal evidence for the critical

156 involvement of sequential and spinal level restricted expression of Shh by VZD for scaling of

157 OPC production along the neuraxis. 


\section{Results:}

\section{Shh expression in the ventral spinal cord}

To examine the contributions of different sources of Shh in the ventral spinal cord to pMN domain activity at the time of the transition from MN to OPC production we first expanded on previous descriptions of Shh expression during spinal cord development. We used a gene expression tracer and conditional loss of function allele of Shh (Shh-nLZ ${ }^{\mathrm{C} / \mathrm{C}}$, abbreviated Shh ${ }^{\mathrm{C} / \mathrm{C}}$ ) in which a bicistronic mRNA is transcribed from the un-recombined Shh locus that encodes Shh and nuclear targeted LacZ (Gonzalez-Reyes, Verbitsky et al. 2012). The allele allows the quantification of the numbers of cells that express Shh and the determination of Shh ablation efficiencies in response to Cre activity with single-cell resolution. This approach reveals developmental stage- and spinal level- specific patterns of Shh expression and relative contributions to ventral Shh production from at least 4 distinct cell populations. At brachial levels at E12.5 we find Shh in all cells of the MFP (defined by co-expression with FoxA2 and situated at the ventral midline stacking 4-5 cells high along the ventral to dorsal axis), LFP (defined by reduced levels of FoxA2 and Shh compared to MFP, situated immediately dorsal to the MFP and stacking about 3-4 cells high along the ventral to dorsal axis), LFP* (defined by coexpression of Nkx2.2 and Shh and situated in part at the lateral edges of the LFP and in part as isolated cells flanking the p3 domain), and in 30\% of all motor neurons (MNs) of the lateral motor column (LMC, defined by co-expression with Hb9 and lateral position in the ventral horns) (Fig. 1). In contrast, at thoracic and lumbar levels at E12.5, we find Shh expression only in MFP, LFP*, and LFP (Fig. 1). Based on numbers of nLacZ+ cells present at E12.5 we estimate that about $57 \%$ of Shh production occurs by MFP, 30\% by the collective LFP and 13\% by MNs at brachial levels while about 50\% of Shh production occurs each by MFP and LFP at 
192 thoracic and lumbar levels (Fig. 1B). The onset of Shh expression in these tissues is sequential 193 and overlaps with both MN and OPC production (Fig. 1C), suggesting the possibility to dissect 194 each source's Shh contribution to pMN activity.

At E13.5 lumbar LMC MNs begin to express Shh resulting in a pattern of expression that is qualitatively similar to brachial levels at E12.5 (Fig. S2A). By E14.5 medial motor column

197 (MMC) MNs at all spinal segments begin to express Shh (Fig. S1A). At P20 Shh expression occurs in MNs, V0 cholinergic neurons, and remaining FP cells at all spinal cord segments (Fig.

S1B and S2C). We observe a similar temporal and segmental pattern of Shh expression in the 200 developing chick spinal cord (Fig. S1C).

To investigate the role of Shh signaling from these Shh sources onto the pMN domain,

202 we generated a series of mouse lines with conditional and in part overlapping ablation of Shh.

203 We used ChAT-Cre (ChAT $\mathrm{Shh}^{-/-}$) to target MNs, Nestin-Cre (Nestinshh ${ }^{-{ }^{-}}$) to target all Shh

204 expressing VZD (MNs, LFP, and LFP*), and Olig2-Cre (Olig2 $\mathrm{Shh}^{-/}$), to target MNs, LFP, and 205 MFP.

At E12.5 we did not observe Shh recombination in MFP cells in ChAT Shh $^{-1-}$ mutants.

207 Nestin $_{\text {Shh }^{-/-}}$mutants had a few MFP cells which displayed Cre activity, but this ablation was

208 insignificant (Fig. 1D and 1G). However, in Olig2 $\mathrm{Shh}^{-/-}$mutants the Shh recombination

209 efficiency among MFP cells in brachial and thoracic spinal segments revealed a significant

$210 \sim 44 \%$ and $\sim 39 \%$ loss resp. (Fig. 1D and 1G). We found no recombination of Shh in the LFP or

$211 \mathrm{LFP}^{*}$ in $\mathrm{ChAT}_{\mathrm{Shh}^{-/-}}$at brachial or thoracic segments (Fig. 1D, E, H). Consistent with the

212 previous reported expression of Nestin-Cre in all VZD between E10.5 to E12.5 (Kramer et al.,

213 2006), and transient expression of Olig2-Cre in all VZD of the pMN domain and ventral to it

214 (Ribes and Briscoe, 2009), we find near complete ( 80\%, and 90\% resp.) ablation of Shh from 
215 the LFP and LFP* in both Nestin $\mathrm{Shh}^{-/-}$and Olig2 $\mathrm{Shh}^{-/-}$in brachial segments (Fig. 1D, E, H). At

216 thoracic segments LFP recombination was less efficient at $\sim 60 \%$ and $\sim 72 \%$ for $\mathrm{Nestin}_{\mathrm{Shh}^{-/-}}$and

217 Olig2 $\mathrm{Shh}^{-/-}$resp. LFP* recombination was $\sim 77 \%$ and $\sim 94 \%$ for Nestin $\mathrm{Shh}^{-/-}$and Olig2 $\mathrm{Shh}^{-/-}$resp.

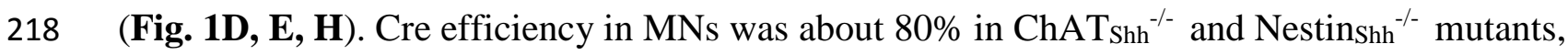

219 and 98\% for Olig2 Shh $^{-/-}$(Fig. 1F and 1G). The location of Shh expression and the varied degrees

220 of ablation of Shh at E12.5 are schematically summarized in Fig. 1J.

221

Using a conditional reporter allele (Fig. 2A), we find that Olig2-Cre but not Nestin-Cre is

222 active in the MFP prior to notochord (NC) regression at E10.5 resulting in the ablation of Shh

223 from $46 \pm 5.1 \%$ and $8.5 \pm 2.8 \%$ resp. of FoxA2+ cells (Fig. 2 B and 2C). These results reveal that

224 the degree of ablation of Shh from MFP in Nestin Shh $^{-/-}$and Olig2 $\mathrm{Shh}^{-/-}$animals is established at

225 the time of MN production and remains fixed. The drastic loss of Shh expression in the MFP

226 already at E10.5 in Olig2 $\mathrm{Shh}^{-/-}$animals prompted us to ascertain a possible patterning defect along

227 the ventral midline. Consistent with previous reports that Shh expression by the notochord (NC)

228 is sufficient for the establishment of precursor domains in the ventral spinal cord (Dessaud,

229 Ribes et al. 2010, Yu, McGlynn et al. 2013) we find that the relative location and size of the p3-

230 (Nkx2.2), pMN- (Olig2) and p0- (Dbx1) domains, and the location of the ventral border of the

231 Pax6 expression domain are indistinguishable between Olig2 ${ }_{\mathrm{Shh}^{-/}}$and control at E10.5 (Fig. 2D

232 and 2E).

Together, the varied degrees of quantifiable and source selective ablation of Shh from the

234 ventral spinal cord and the preservation of early ventral tube patterning indicated that this set of

235 recombinant mouse lines might be informative in the investigation of the effect of VZD sources

236 of Shh onto the pMN domain during MN and OPC generation. 


\section{Shh signaling from MFP, but not VZD sources influences MN generation}

We investigated whether ablating Shh from VZD sources would impact the generation of MNs from Olig2 precursors of the pMN domain. We analyzed columnar pattern, relative distribution of MNs among columns, and absolute numbers of MNs of different columnar identity at brachial and thoracic levels. We first visualized MN columnar organization by immunostainings for MMC (Hb9+ Lhx3+), LMC $\mathrm{M}\left(\mathrm{Hb} 9+\right.$ Isl1/2+), and $\mathrm{LMC}_{\mathrm{L}}(\mathrm{Hb} 9+$, Isl1/2-, Lhx3-) at brachial (Fig. 3A) and MMC (Hb9+, Isl1-), HMC (Hb9+, Isl1/2+), and PGC (Hb9-, nNos+) at thoracic (Fig. 3E) and found no apparent differences in the staining pattern either among ChAT $\mathrm{Shh}^{-/-}$, Nestinshh ${ }^{-/-}$, Olig2 $\mathrm{Shh}^{+/-}$, or Olig2 $\mathrm{Shh}^{-/-}$compared to Shh ${ }^{\mathrm{C} / \mathrm{C}}$ controls. Further supporting unaffected MN positioning and patterning, we find inconspicuous ventral root formation in Olig2 Shh $^{-/-}$compared to Shh ${ }^{\mathrm{C} / \mathrm{C}}$ controls at E10.5 and E12.5. (Fig. S3).

Quantification of MN numbers revealed no differences in ChAT $\mathrm{Shh}^{-/-}$and Nestinshh ${ }^{-/-}$ compared to Shh ${ }^{\mathrm{C} / \mathrm{C}}$ controls at brachial and thoracic levels. In contrast, in Olig2 $\mathrm{Shh}^{+/-}$and Olig2 $\mathrm{Shh}^{-1-}$ we find a $22 \%$ and 38\%, resp. reduction in the numbers of total MNs at brachial (Fig. 3B), and 22\% and 32\% at thoracic levels compared to Shh ${ }^{\mathrm{C} / \mathrm{C}}$ controls (Fig. 3F). Since the production of late born MNs could be affected to a greater extent than early born MNs by the ablation of Shh from previously born VZD, we compared the relative size of the MN columns and the numbers of late born MNs just emerging from the ventricular zone at E12.5. We found that MNs attained columnar identities in normal relative proportions in all genotypes (Fig. 3D and 3H). However, quantification of migrating late born Hb9+ MNs showed a dose-dependent reduction of $~ 10 \%$ in Olig2 $\mathrm{Shh}^{+/-}$and 47\% in Olig2 $\mathrm{Shh}^{-/-}$in brachial, and 23\% and 47\% resp. in thoracic segments, suggesting that the deficit in $\mathrm{MN}$ generation that we observe in Olig2 $\mathrm{Shh}^{+/}$and Olig2 $\mathrm{Shh}^{-/-}$mice is greatest towards the end of MN production (Fig. 3I). We did not observe a 
261 decrease in numbers of late born migrating MNs in $\mathrm{ChAT}_{\mathrm{Shh}^{-/}}$or Nestin $\mathrm{Shh}^{-/-}$. We next examined

262 if the earlier deficits in MN generation in Olig2 $\mathrm{Shh}^{-/-}$mice could be overcome by reduced

263 apoptosis during the phase of programmed cell death. To this end, we found reduced levels of

264 Caspase3+ Hb9+ brachial MNs in Olig2 $\mathrm{Shh}^{-/-}$at E12.5 indicating that reduced cell death of MNs

265 at least in part will compensate for a reduced rate of MN production in Olig2 Shh $^{-/-}$animals (Fig.

$2663 \mathbf{3})$.

We associated the degree of reduction in the numbers of MNs with the tissue specific efficiency of Shh ablation in $\mathrm{ChAT}_{\mathrm{Shh}^{-{ }^{-}}}$, Nestin $\mathrm{Shh}^{-/-}$, and Olig2 $\mathrm{Shh}^{-/-}$(Fig. 3K). The 80\% efficient ablation of Shh from MNs at brachial levels as well as the near complete ablation of Shh from the LFP in Nestin Shh $^{-/-}$, has no effect on MN numbers at E12.5. In contrast, the near complete

271 ablation of Shh from MNs, LFP and about 50\% of MFP in Olig2 shh $^{-/-}$results in a Shh dose-

272 dependent reduction of MN numbers at all levels and in all MN columns (Fig. 3K, orange line).

273 Together these results reveal that MN differentiation can proceed in the absence of Shh signaling

274 from the ventricular zone derivatives MN and LFP, but the efficacy of MN generation becomes 275 progressively impacted by dose-dependent reductions in Shh signaling from the MFP.

278 the onset of gliogenesis in a spinal level specific manner.

279 Previous studies did not evaluate the contribution from individual Shh sources for the

280 maintenance of established precursor domains after NC retraction. We therefore next

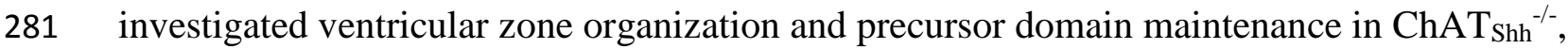

282 Nestin $_{\mathrm{Shh}^{-/-}}$, and Olig2 $\mathrm{Shh}^{-/-}$. We find that the relative location and distance to each other of the p3, 283 pMN, and p0 precursor domains are preserved in $\mathrm{ChAT}_{\mathrm{Shh}^{-/-}}$, Nestin $\mathrm{Shh}^{-{ }^{--}}$, and Olig2 ${ }_{\mathrm{Shh}^{-/-}}$at E12.5 
284 (Fig. 4A). However, we observe a Shh source and dose-dependent, spinal level-specific decline 285 in the numbers of Olig2+ cells in the pMN domain of $\mathrm{ChAT}_{\mathrm{Shh}^{-/-}}$, Olig2 ${ }{ }^{+/-}$, $\mathrm{Nestin}_{\mathrm{Shh}^{-/}}{ }^{- \text {and }}$ 286 Olig2 $\mathrm{Shh}^{-/-}$compared to Shh ${ }^{\mathrm{C} / \mathrm{C}}$ or Olig2-Cre control (Fig. 4B and 4C). In $\mathrm{ChAT}_{\mathrm{Shh}^{-/-}}$we find a 26\% decrease in pMN/Olig2+ cells (pMN $\mathrm{Olig}^{2}$ ) at brachial levels (but not at thoracic or lumbar) consistent with expression of Shh in MNs at brachial but not yet in MNs at thoracic and lumbar levels which will begin to express Shh about one day later (Fig. 4C). Upon more detailed analysis, we find the effect of MN Shh to become progressively more pronounced during the rapid enlargement of the pMN that occurs at brachial segments between E12.5 to E12.75 (Fig. 4D and 4E). The numbers of pMNolig2 ${ }^{+}$cells in Nestin Shh $^{-/-}$displays an anterior-posterior progressive decrease of $40 \%$ at brachial, $51 \%$ at thoracic, and $59 \%$ at lumbar segments (Fig. 4B and 4C). The most severely affected genotype is Olig2 $\mathrm{Shh}^{-/-}$with a decrease in pMN $_{\text {Olig }}{ }^{+}$cells of $66 \%$ at brachial, $61 \%$ at thoracic, and $72 \%$ at lumbar (Fig. 4B and 4C). We next associated the degree of reduction in the numbers of $\mathrm{pMN}_{\text {Olig2 }}{ }^{+}$cells at brachial and thoracic levels with the time of onset and tissue specific efficiency of Shh ablation in $\mathrm{ChAT}_{\mathrm{Shh}^{-/-}}$, Olig2 $\mathrm{Shh}^{-/-}$, and Nestin $\mathrm{Shh}^{-/-}$(Fig. 4F). In controls, we find about 19\% more pMNolig2 ${ }^{+}$ cells at brachial than thoracic segments. The $80 \%$ efficient ablation of Shh from MNs in $\mathrm{ChAT}_{\mathrm{Shh}^{-/-}}{ }^{-1}$ reduces the numbers of $\mathrm{pMN}_{\mathrm{Olig} 2}{ }^{+}$cells at brachial levels to those present in controls at thoracic levels while the ablation of Shh from MNs has no effect on the numbers of pMN $\mathrm{Olig}^{+}$ cells at thoracic levels (Fig. 4F, red line). Nestinshh ${ }^{-/-}$and Olig2 $\mathrm{Shh}^{-/-}$exhibit near complete ablation of Shh from MNs and LFP, but significantly different ablation efficiencies in the MFP, resulting in a reduction of $\mathrm{pMN}_{\text {Olig2 }}{ }^{+}$cells at brachial levels that scales with the degree of Shh ablation from the MFP. At thoracic levels, however, we find the same magnitude in the reduction of the numbers of pMN $\mathrm{Olig}^{2}$ cells in Nestin $\mathrm{Shh}^{-{ }_{-}}$and Olig2 $\mathrm{Shh}^{-/-}$despite of a much greater total 
307

308

309

310

311

312

313

314

315

316

317

318

319

320

321 322 gliogenesis of OPCs.

323

324

325

326

327

328 segments.

reduction in numbers of Shh producing cells by Olig2-Cre compared to Nestin-Cre. This observation suggests that Shh produced by LFP cells, though few in number, has a disproportionate significance compared to MFP derived Shh for $\mathrm{pMN}_{\mathrm{Olig} 2}{ }^{+}$cells at thoracic

Next, we determined if the decreased numbers of $\mathrm{pMN}_{\text {Olig2 }}{ }^{+}$cells is the result of diminished initial specification or a failure of maintenance. We lineage traced Olig2 cells in Olig2 $\mathrm{Shh}^{-/-}$mutants, Olig2 $\mathrm{Shh}^{+/-}$controls, and Olig2-Cre controls using the R26mT/mG reporter allele from which myristylated GFP is expressed in all derivatives of Olig2 expressing cells and immunostained for Olig2 at E12.5 (Fig. 5A). We observe GFP expression in the ventral spinal cord forming a dorsal boundary at a similar relative distance to the MFP in mutants and controls but a decline in pMN Olig2 $^{+} \mathrm{GFP}+$ double positive cells in mutants compared to controls. Notably, the absence of Olig2 expressing cells within the GFP labeled area in mutants is most pronounced in the dorsal half of the pMN domain. Together, these results demonstrate that ongoing Shh signaling originating from VZD in addition to MFP are critical for the selective maintenance of $\mathrm{pMN}_{\text {Olig2 }}{ }^{+}$cells once the influence of notochord Shh has waned and the pMN switches to

Providing further evidence for decreased pMN domain activity at the beginning of OPC production at E12.5 we find a 3-fold reduction in the size of $\mathrm{p}^{*}$ precursor domain in Olig2 Shh $^{-/-}$ compared to controls (Fig. 5B and 5C). The p* domain forms at the ventral border of the pMN domain and is marked by Olig2+/Nkx2.2+ cells (Agius et al., 2004). Interestingly, we found LFP* cells (which we define as Nkx2.2+ nLacZ+ cells) in direct contact with Nkx2.2+ Olig2+ double positive cells of the $\mathrm{p}^{*}$ domain in $\mathrm{Shh}^{\mathrm{C} / \mathrm{C}}$ controls, highlighting a cyto-architectural 
arrangement that could underpin the disproportionate importance of LFP compared to MFP shh for the maintenance of the pMN olig2 $^{+}$cell population (Fig. 5B).

\section{Diminishment of $\mathrm{pMNolig}^{+}$cells during the phase of ventral oligodendrogenesis results in reduced OPC production.}

Reduced Shh signaling originating from MNs, LFP, or MFP leaves the pMN domain impoverished of $\mathrm{pMN}_{\mathrm{Olig}^{+}}{ }^{+}$cells at the beginning of oligodendrogenesis (Fig. 4). Nevertheless, the $\mathrm{pMN}_{\text {olig2 }}{ }^{+}$cell population could recover during OPC production by increased precursor recruitment from dorsal ventricular precursor domains (Ravanelli and Appel 2015), proliferation of remaining $\mathrm{pMN}_{\mathrm{Olig} 2}{ }^{+}$precursor cells, or increased differentiation and amplification of OPC fated cells that have left the pMN domain. We therefore first visualized the size of $\mathrm{pMN}_{\text {Olig2 }}{ }^{+}$ population at the end of ventral oligodendrogenesis at E14.5. We find a moderate reduction in the numbers of $\mathrm{pMN}_{\mathrm{Olig} 2}{ }^{+}$cells in $\mathrm{ChAT}_{\mathrm{Shh}^{-/-}}$and an almost complete absence of $\mathrm{pMN} \mathrm{Olig}^{+}$cells in Nestinshh ${ }^{-/-}$and Olig2 $\mathrm{Shh}^{-/-}$compared to Shh ${ }^{\mathrm{C} / \mathrm{C}}$ controls suggesting that increased recruitment of precursors to the pMN domain does not occur in mutants (Fig. S4 and Fig. 6A). We then determined whether $\mathrm{pMN}_{\text {Olig2 }}{ }^{+}$cells and/or migrating OPCs in Olig2 $\mathrm{Shh}^{-1-}$ increase their rate of proliferation during the phase of OPC production. We injected EdU into pregnant dams at E11.5, E12.5, and E13.5 and quantified the numbers of $\mathrm{pMN}_{\text {Olig2 }}{ }^{+}$cells $24 \mathrm{~h}$ later. We found comparable broad EdU+ labeling throughout the ventricular zone of Olig2 $\mathrm{Shh}^{-/-}$mutants and controls, suggesting overall progenitor proliferation is not affected in mutants (Fig. 6A). Within the pMN domain we observe a $\sim 25 \%$ decrease in the numbers of $\mathrm{pMN}_{\text {Olig2 }}{ }^{+}$cells in $\mathrm{Shh}^{\mathrm{C} / \mathrm{C}}$ controls over the course of OPC production from E12.5 to E14.5 (Fig. 6B). In contrast, numbers of pMN olig2 $^{+}$ cells in Olig2 $\mathrm{Shh}^{-/-}$mutants decline to near undetectable levels during the same period indicating a 
352 precocious exhaustion of the $\mathrm{pMN}_{\mathrm{Olig} 2}{ }^{+}$cell population during OPC generation (Fig. 6B). We

353 next determined the rate of proliferation of $\mathrm{pMN}_{\text {Olig2 }}{ }^{+}$cells in controls and mutants. In controls,

354 we find a similar proliferative rate of about 47\% of pMN olig2 $^{+}$cells at E12.5, E13.5 and E14.5. In

355 contrast, in Olig2 $\mathrm{Shh}^{-/-}$we find the rate of proliferation to be reduced to 37\% at E12.5 and E13.5,

356 followed by a further decrease to $16 \%$ by E14.5 (Fig. 6C). These results indicate that the

357 precocious exhaustion of the $\mathrm{pMN}_{\mathrm{Olig} 2}{ }^{+}$cell population is associated with a reduced proliferation

358 rate of precursor cells during OPC production which is compounded by reduced numbers of

359 pMN Olig2 $^{+}$cells that are present at the beginning of OPC production.

We next tested whether OPC production in Olig2 $\mathrm{Shh}^{-/-}$recovers through increased

362 EdU+ Olig2+ cells in the mantle zone (Fig. 6D). While there are very few Olig2+ cells in the

363 mantle zone of mutants and controls at E12.5, with ongoing expansion of these cells, we find a 3-

364 fold and 15-fold reduction of Olig2+ cells at E13.5 and E14.5, resp.in mutants compared to

365 controls (Fig. 6E). The rate of proliferation among Olig2+ cells in the mantle zone in Olig2 $\mathrm{Shh}^{-/-}$

366 is similar at E13.5 and E14.5 compared to controls suggesting that OPCs in mutants do not

367 amplify at an increased rate compared to controls (Fig. 6F). The cells that do emerge from the

$368 \mathrm{pMN}$ in Olig2 $\mathrm{Shh}^{-/-}$disperse as rapidly as their control counterparts, resulting in a ventral spinal

369 cord that is populated with nascent OPCs with a 15-fold lower density compared to controls (Fig.

370 S5). Additionally, we examined OPC proliferation at E14.5 in posterior thoracic and lumbar

371 segments and found no detectable increase in proliferation rate in any of the pMN, mantle, or

372 white matter (WM) areas (Fig. S6). These results reveal that the yield of the pMN domain during

373 OPC production largely determines the numbers of OPCs that settle in white and grey matter.

374 Thus the scaled production of OPCs and oligodendrocyte along the anterior posterior extent of 
375 the spinal cord must at least in part be determined by the patterned expression of VZD ${ }_{\text {shh }}$ that we

376 find to be critical for the maintenance of the pMNolig2+ precursor population.

377

378

379

380

381

382

383

384

385

386

387

388

389

390 


\section{Discussion:}

392 Our study provides causal evidence that the sequential and patterned expression of Shh by

393 previously specified cell types in the ventral spinal cord is critical for scaled oligodendrocyte

394 precursor specification along the anterior posterior axis of the developing spinal cord. We took

395 advantage of neural tube development as an established model system to reveal that Shh-

396 expressing signaling centers become established among post mitotic derivatives of ventricular

397 zone differentiation (VZD $\left.{ }_{\text {Shh }}\right)$ in a temporally- and spatially-patterned manner as development

398 proceeds. We find that VZD

399 numbers to previously specified neurons. Our data provides genetic evidence in support of the

400 hypothesis that extra-midline sources of Shh are critical for switching neurogenesis to

401 gliogenesis and add a novel mechanism that contributes to pattern scaling along the anterior to

402 posterior axis. Our observations do not rule out contributions of other well-established cell-

403 autonomous and cell non-autonomous mechanisms that adapt morphogen function and allow

404 pattern scaling (Houchmandzadeh, Wieschaus et al. 2005, Ben-Zvi and Barkai 2010,

405 Hamaratoglu, de Lachapelle et al. 2011, Ben-Zvi, Fainsod et al. 2014, Uygur, Young et al. 2016),

406 but provide a mechanism by which Shh mediated signaling from the midline in the ventral neural

407 tube becomes progressively augmented such that Shh signaling remains a relevant instructive

408 signal despite rapid growth.

\section{Sequential expression and function of VZD shh.}

Despite its complexity, development is orchestrated by the actions of just a handful of

411 morphogens. The temporal and spatial segregation of developmental fields that are patterned by

412 morphogens can allow the same morphogen to play an instructive role repeatedly and at multiple 
413

414

415

416

417

418

419

420

421

422

423

424

425

426

427

428

429

430

431

432

433

434

435

anatomic regions specifying vastly different cell types and tissues. However, in the developing spinal cord all cell types are descendants of the same developmental field, the ventricular zone, yet the same morphogen, Shh, is involved in the sequential specification of multiple cell types (Dessaud, McMahon et al. 2008). The number of source tissues of Shh in the ventral spinal cord expands concomitantly with development, suggesting that “moving the Shh source” might play an important role (Danesin and Soula, 2017). We reassessed Shh expression in mice using a nuclear targeted LacZ based gene expression tracer allele and verified the principle findings in chick by RNA in situ. The advantage of the gene expression tracer allele is that the identity, location and numbers of Shh expression can be determined with single-cell resolution. Ablating Shh and nLacZ by Nestin-Cre, which is expressed in the ventricular zone, reveals that one half to one third of all Shh expressing cells in the ventral spinal cord are ventricular zone descendants at the time that Shh signaling strength within the pMN domain rises coincident with the switch from neurogenesis to gliogenesis (Dessaud, Yang et al. 2007, Balaskas, Ribeiro et al. 2012, Touahri, Escalas et al. 2012, Kicheva, Bollenbach et al. 2014, Kicheva and Briscoe 2015). While the gene expression tracer allele cannot be used to draw conclusions about the relative Shh signaling strength in the ventricular zone that is contributed by VZD ${ }_{\text {Shh, the anatomic }}$ arrangement of these sources and the genetic ablation of Shh from these sources suggests a disproportionate effect on the activity of the pMN domain. The LFP proper extends the midline source of Shh by several cell diameters more dorsally as previously observed (Charrier et al., 2002). A subset of LFP cells, which we designate here as LFP* cells, co-express Nkx2.2 and Shh (Al Oustah, Danesin et al. 2014) and are in direct contact with cells that co-express the Shh highthreshold genes Nkx2.2+ Olig2+ and form the $\mathrm{p}^{*}$ domain at the beginning of oligodendrogenesis (Fu, Qi et al. 2002, Traiffort, Zakaria et al. 2016). At the same developmental stage, we detect 
expression of Shh in the nascent lateral, but not medial, MN column in mice and chick. Shh can be released from the axonal as well as the dendritic compartment of neurons ((Beug, Parks et al. 2011). Hence nascent MNs could secrete Shh via dendrites or possibly trailing cellular processes close to the pMN domain. Together, the spatial and temporal pattern of VZDshh expression that we observe is consistent with the results from our selective gene ablation studies which demonstrate that these sources of Shh influence pMN domain activity, a speculation put forward previously in regard of the function of LFP ${ }_{\text {Shh }}$ (Danesin and Soula 2017).

A striking feature of the phenotype of Shh ablation from VZD is the temporal and qualitative segregation of the effects on MN and OPC production. VZD $\mathrm{Shh}_{\text {h }}$ has no detectable effect on MN production or the extent of programmed cell death of MNs in our paradigms. In contrast, ablation of VZD $D_{\text {Shh }}$ results in severely reduced OPC production: (1) During the period of OPC production the initial 2-fold diminishment of $\mathrm{pMN}_{\text {Olig2 }}{ }^{+}$cells increases to a more than 10-fold reduction in pMNOlig2+ cells compared to controls. (2) During the same period, the numbers of Olig2+ cells that emerge from the pMN domain drop 10-fold. (3) The proliferation rate of these nascent OPCs is equal to or lower compared to their control counterparts. Together these observations reveal that the numbers of OPCs that emigrate from the pMN domain and settle in the white and grey matter are determined mainly by the size of the $\mathrm{pMN}_{\text {Olig2+ }}$ precursor cell population.

The relative contribution of $\mathrm{VZD}_{\text {Shh }}$ to regulating the size of the $\mathrm{pMN}_{\mathrm{Olig} 2+}$ precursor cell population is spinal level specific. For example, the ablation of VZD ${ }_{\text {shh }}$ results in a pMN olig2 $^{+}$ loss of about $40 \%$ at brachial levels. Half of that effect at brachial levels can be attributed to the expression of $\mathrm{MN}_{\mathrm{Shh}}$ since the ablation of Shh from cholinergic neurons by ChAT-Cre alone results in an almost $26 \%$ reduction in the size of the $\mathrm{pMN}_{\text {olig2 }}{ }^{+}$population (Fig. $\left.3.2 \mathrm{~B}\right)$. The

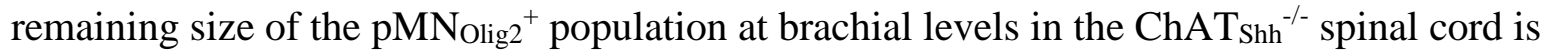


similar to the average size of the $\mathrm{pMN}_{\text {Olig2 }}{ }^{+}$domain at thoracic levels in control spinal cords.

460

461

462

463

464

465

466

467

468

469

470

471

472

473

474

475

476

477

478

479

480

481

Since thoracic MNs do not express Shh until the end of OPC production at E14.5, our

observations reveal that the increased size of the pMN domain at brachial levels is dependent on $\mathrm{MN}_{\text {Shh. }}$ Thus, the selective expression of $\mathrm{MN}_{\text {Shh }}$ at brachial and lumbar levels provides a mechanism for ensuring a proportionate increase in the production of OPCs at brachial and lumbar - compared to thoracic- levels that is matched to the increased numbers of MNs at limb levels.

\section{Potential mechanisms of actions of VZDShh.}

Does Shh from different sources have distinct functions in the ventricular zone of the ventral spinal cord? Three observations support origin specific functions of Shh in the ventral

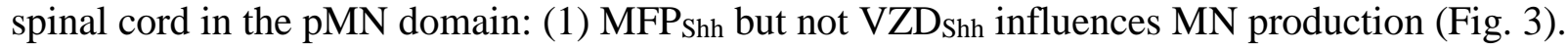
Consistent, ablation of Shh in the MFP by Olig2-Cre is complete at the beginning of MN production while ablation of Shh in VZD by Nestin-Cre only begins towards the end of MN generation (Fig. 1). In further support of a critical role of $\mathrm{MFP}_{\text {Shh }}$ in MN generation and consistent with previous findings (Yu, McGlynn et al. 2013), we find a Shh gene dose-dependent reduction of the numbers of MNs of similar magnitude among early and late forming $\mathrm{MN}$ columns as well as late born MNs still in transit at E12.5. Hence, based on the timing of Shh expression and the consistent deficit in $\mathrm{MN}$ production throughout the period of $\mathrm{MN}$ generation, the reduced rate of MN production must be associated with the reduction of midline-derived Shh rather than VZD-derived Shh. Strikingly, however, whether Shh expression is ablated from all VZDs (Nestin $\mathrm{Shh}^{-/-}$) or partially from the MFP in addition to LFP and MNs (Olig2 $\mathrm{Shh}^{-/}$), the pMN domain is left with similar strongly reduced numbers of $\mathrm{pMN}_{\text {Olig2 }}{ }^{+}$cells at the end of $\mathrm{MN}$ production (Fig. 2). Since ventral precursor domains form normally and a full complement of 
$482 \mathrm{pMN}_{\text {Olig2 }}{ }^{+}$cells is induced in Olig2 $\mathrm{Shh}^{-/-}$(Fig. 1), these results point to distinct functions of Shh derived from the MFP and VZDs in pMN domain activity: Our data indicates that MFP Shh $_{\text {Sh }}$ determines the rate of $\mathrm{MN}$ production while VZD $\mathrm{Shh}_{\text {is }}$ critical to counteract the exhaustion of the $\mathrm{pMN}_{\mathrm{Olig} 2}{ }^{+}$population during MN production. (2) We find that the high threshold, Shh dependent and p* domain defining co-expression of Nkx2.2 and Olig2 (Fu, Qi et al. 2002) occurs in cells

487 that are in close proximity to LFP* cells. Ablation of VZD ${ }_{\text {shh }}$ results in a 3-fold reduction in the numbers of Nkx2.2/Olig2 expressing cells at E12.5 (Fig. 4). Additional ablation of Shh from $50 \%$ of the MFP in Olig2 $\mathrm{Shh}^{-/-}$did not increase the severity of this phenotype (Fig. 4). Thus, consistent with the anatomic juxtaposition of LFP cells to $\mathrm{p}^{*}$ domain cells our gene ablation studies demonstrate that $\mathrm{VZD}_{\text {Shh }}$ is critical for the production of the Nkx2.2 expressing

492 subpopulation of ventral oligodendrocyte lineage cells. (3) The dorsal most aspects of the pMN 493 domain is almost completely devoid of Olig2+ expressing cells at the end of MN production at 494 E12.5 in Nestinshh ${ }^{-/-}$and Olig2 $\mathrm{Shh}^{-/-}$(Fig. 2). Given that early pioneer OPCs elaborate cellular 495 contacts selectively with MNs (Osterstock, Le Bras et al. 2018) it seems plausible that the LFP

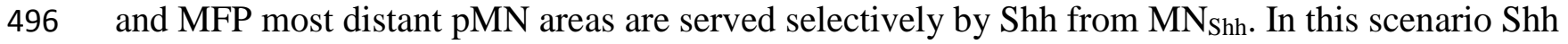
497 signaling from different sources might subdivide the pMN domain into sub-regions from which 498 distinct oligodendrocyte subtypes might emerge (Dimou and Simons 2017, Ravanelli, Kearns et 499 al. 2018) Dependent on the mode of delivery, VZD ${ }_{\text {Shh }}$ could also exhibit distinct modes of

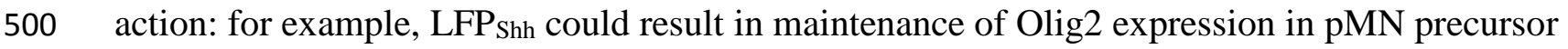
501 cells while $\mathrm{MN}_{\mathrm{Shh}}$ could attract precursor cells to migrate into the pMN domain from the dorsal 502 ventricular zone as is observed in zebrafish (Ravanelli and Appel, 2015).

503 Together, our data provides genetic evidence in support of the idea that morphogen signaling centers 504 are established sequentially in the developing ventral spinal cord. These new "organizer tissues" express 
506 spinal cord grows. These Shh sources are critically involved in the switch of neurogenesis to

507 oligodendrogenesis in the pMN domain. Endowing VZDs with morphogenic activity makes subsequent

508 differentiation conditional to the completion of previous developmental milestones in the ventral spinal

509 cord. Further, expression of the morphogen linked to the numbers and types of VZDs produced,

510 provides a mechanism that could ensure scale invariance in regard of neuron and glia production along

511 the anterior-posterior axis of the spinal cord.

512

513 Acknowledgements: We thank Artur Kania for comments on earlier versions of the manuscript.

514 We thank Thomas Jessell, Susan Morton, Ben Novitch, Sam Pfaff for reagents. LS performed the

515 experiments, analyzed data and wrote the manuscript. AHK conceived the work, interpreted the

516 results and wrote the manuscript. LS was funded in part by the Graduate Center of the City

517 University of New York.

518

519

520

521

522

523

524

525

526

527

528

529 
Materials and Methods

Transgenic Mice

538 All animal experiments were approved by the Institutional Animal Use Care Committee at 539 CUNY. The following mouse strains were used and genotyped as described previously: Shh540 nLZ ${ }^{\mathrm{L} /+}$ animals (Gonzalez-Reyes et al., 2012), Chat-Cre (Rossi et al., 2011), Olig2-Cre (Dessaud 541 2007), Nestin-Cre (Tronche et al., 1999), Rosa26 ${ }^{\mathrm{mT} / \mathrm{mG}}$ (Muzumdar et al., 2007). Mice were 542 maintained on a C57BL/6 background. Noon on the day of the plug was considered E0.5. Mice 543 were kept on a 12 hr dark/light cycle and the day of birth designated P1. For E12.25, E12.50, and 544 E12.75 pMN analysis, pregnant dams were sacrificed at E12.5 according to plug date and 545 embryos were binned into three groups (E12.25, E12.50, and E12.75), based on how many 546 Olig2+ cells have migrated out of the pMN domain. Embryo sections which had an average of 547 less than 5 cells migrate out of the pMN were considered 12.25, 5-20 cells migrating out 548 E12.50, and $>20$ cells migrating out - E12.75. 
552 Pregnant dams received EdU (5-ethynyl-20 -deoxyuridine, Invitrogen) dissolved in PBS by

553 intraperitoneal injection (50 mg/kg) and sacrificed after 24 hours. Tissue sections were stained

554 using the Click-iT Plus EdU Alexa Fluor 647 Imaging Kit (Thermofisher).

555

556

557 Tissue Processing

558

559 All mice were sacrificed using an overdose of anesthetic, subjected to transcardial perfusion with

$5604 \%(\mathrm{w} / \mathrm{v})$ paraformaldehyde (PFA) in $0.1 \mathrm{M}$ PBS pH 7.4. Spinal cords and embryos were

561 dissected, postfixed in $4 \%$ PFA for $1 \mathrm{hr}$ at $4^{\circ} \mathrm{C}$, cryoprotected with $30 \%(\mathrm{w} / \mathrm{v})$ sucrose in $0.1 \mathrm{M}$

562 PBS for $24-48 \mathrm{hr}$, embedded and frozen in OCT medium, and stored at $-80^{\circ} \mathrm{C}$. Tissues were

563 sectioned at $20 \mu \mathrm{m}$ and collected onto glass slides.

564

565

Immunocytochemistry and Microscopy

566

567 20um thick spinal cord cryosections were air dried for $30 \mathrm{~min}$. Then sections were washed with

568 PBS for 10 mins and with 0.3\% [v/v] Triton X-100 in PBS for 20 min. Sections were then pre-

569 treated with blocking solution (10\% [v/v] horse serum and 0.3\% [v/v] Triton X-100 in PBS) for

57090 mins and incubated with primary antibodies overnight at 4C. The next day, following 3 PBS

571 washes the sections were incubated with secondary antibodies for $2 \mathrm{hr}$ at room temperature. A

572 list of all antibodies and compounds used is provided in a table. For cell counts, at least three

573 sections per animal from at least three mice were examined, unless otherwise noted. Images were

574 acquired using a Zeiss LSM880 confocal microscope. 
576 Statistical analysis was performed using Prism 7 (Graphpad Software Inc.) Analysis of multiple

577 groups was made using one-way ANOVA followed by the Tukey or Dunnett's post hoc analysis

578 tests. For 2-groups analyses, unpaired Student's t test was used. The data are presented

579 graphically as: $*(\mathrm{p}<0.05), * *(\mathrm{p}<0.01)$, and $* * *(\mathrm{p}<0.001)$.

580

581

\begin{tabular}{|c|c|c|}
\hline REAGENT & SOURCE & IDENTIFIER \\
\hline \multicolumn{3}{|c|}{ Antibodies } \\
\hline Chicken polyclonal anti beta Galactosidase & Abcam & $\begin{array}{l}\text { Cat\# ab9361, } \\
\text { RRID:AB_307210 }\end{array}$ \\
\hline Goat polyclonal anti beta Galactosidase & Biogenesis & $\begin{array}{l}\text { Cat\# 4600-1409, } \\
\text { RRID:AB_2314510 }\end{array}$ \\
\hline Goat polyclonal anti Choline acetyltransferase & Millipore & $\begin{array}{l}\text { Cat\# AB144P, } \\
\text { RRID:AB_2079751 }\end{array}$ \\
\hline Rabbit polyclonal anti Olig2 & Millipore & $\begin{array}{l}\text { Cat\#AB9610, } \\
\text { RRID:AB_570666 }\end{array}$ \\
\hline Mouse monoclonal anti Nkx2.2 & DSHB & $\begin{array}{l}\text { Cat\# 74.5A5, } \\
\text { RRID:AB_531794 }\end{array}$ \\
\hline Rabbit polyclonal anti nNos & Immunostar & $\begin{array}{l}\text { Cat\# 24431, } \\
\text { RRID:AB_572255 }\end{array}$ \\
\hline Mouse monoclonal Ankyrin G (AnkG) (463) & Santa Cruz & $\begin{array}{l}\text { Cat\# sc-12719, } \\
\text { RRID:AB_626674 }\end{array}$ \\
\hline Mouse monoclonal Lim3 (Lhx3) & DSHB & $\begin{array}{l}\text { Cat\# 67.4E12, } \\
\text { RRID:AB_2135805 }\end{array}$ \\
\hline Rabbit polyclonal Lim1 & Gift Jessell Lab & N/A \\
\hline Guinea Pig polyclonal Hb9 & Gift Jessell Lab & N/A \\
\hline Rabbit polyclonal FoxA2 & Gift Jessell Lab & N/A \\
\hline Rabbit polyclonal Pax6 & Gift Jessell Lab & N/A \\
\hline Rabbit polyclonal Dbx1 & Gift Jessell Lab & N/A \\
\hline
\end{tabular}




\begin{tabular}{|c|c|c|}
\hline Rabbit polyclonal IsI1/1 & Gift Jessell Lab & N/A \\
\hline Rabbit polyclonal anti Nkx2.2 & Gift Jessell Lab & N/A \\
\hline Donkey anti rabbit Alexa 488 & $\begin{array}{l}\text { Jackson } \\
\text { ImmunoResearch }\end{array}$ & $\begin{array}{l}\text { Cat\# 711-545-152, } \\
\text { RRID:AB_2313584 }\end{array}$ \\
\hline Donkey anti mouse Alexa 488 & $\begin{array}{l}\text { Jackson } \\
\text { ImmunoResearch }\end{array}$ & $\begin{array}{l}\text { Cat\# 715-545-150, } \\
\text { RRID:AB_2340846 }\end{array}$ \\
\hline Donkey anti guinea pig Alexa 488 & $\begin{array}{l}\text { Jackson } \\
\text { ImmunoResearch }\end{array}$ & $\begin{array}{l}\text { Cat\# 706-545-148, } \\
\text { RRID:AB_2340472 }\end{array}$ \\
\hline Donkey anti goat Alexa 488 & $\begin{array}{l}\text { Jackson } \\
\text { ImmunoResearch }\end{array}$ & $\begin{array}{l}\text { Cat\# 705-545-147, } \\
\text { RRID:AB_2336933 }\end{array}$ \\
\hline Donkey anti rabbit Cy3 & $\begin{array}{l}\text { Jackson } \\
\text { ImmunoResearch }\end{array}$ & $\begin{array}{l}\text { Cat\# 711-165-152, } \\
\text { RRID:AB_2307443 }\end{array}$ \\
\hline Donkey anti mouse Cy3 & $\begin{array}{l}\text { Jackson } \\
\text { ImmunoResearch }\end{array}$ & $\begin{array}{l}\text { Cat\# 715-165-150, } \\
\text { RRID:AB_2340813 }\end{array}$ \\
\hline Donkey anti guinea pig Cy3 & $\begin{array}{l}\text { Jackson } \\
\text { ImmunoResearch }\end{array}$ & $\begin{array}{l}\text { Cat\# 706-165-148, } \\
\text { RRID:AB_2340460 }\end{array}$ \\
\hline Donkey anti rat Cy3 & $\begin{array}{l}\text { Jackson } \\
\text { ImmunoResearch }\end{array}$ & $\begin{array}{l}\text { Cat\# 712-165-153, } \\
\text { RRID:AB_2340667 }\end{array}$ \\
\hline Donkey anti rabbit Alexa 594 & $\begin{array}{l}\text { Jackson } \\
\text { ImmunoResearch }\end{array}$ & $\begin{array}{l}\text { Cat\# 711-585-152, } \\
\text { RRID:AB_2340621 }\end{array}$ \\
\hline Donkey anti mouse Alexa 594 & $\begin{array}{l}\text { Jackson } \\
\text { ImmunoResearch }\end{array}$ & $\begin{array}{l}\text { Cat\# 715-585-150, } \\
\text { RRID:AB_2340854 }\end{array}$ \\
\hline Donkey anti guinea pig Alexa 594 & $\begin{array}{l}\text { Jackson } \\
\text { ImmunoResearch }\end{array}$ & $\begin{array}{l}\text { Cat\# 706-585-148, } \\
\text { RRID:AB_2340474 }\end{array}$ \\
\hline Donkey anti rat Alexa 594 & $\begin{array}{l}\text { Jackson } \\
\text { ImmunoResearch }\end{array}$ & $\begin{array}{l}\text { Cat\# 712-585-153, } \\
\text { RRID:AB_2340689 }\end{array}$ \\
\hline Donkey anti chicken Cy5 & $\begin{array}{l}\text { Jackson } \\
\text { ImmunoResearch }\end{array}$ & $\begin{array}{l}\text { Cat\# 703-175-155, } \\
\text { RRID:AB_2340365 }\end{array}$ \\
\hline Donkey anti goat Cy5 & $\begin{array}{l}\text { Jackson } \\
\text { ImmunoResearch }\end{array}$ & $\begin{array}{l}\text { Cat\# 705-175-147, } \\
\text { RRID:AB_2340415 }\end{array}$ \\
\hline Donkey anti mouse Cy5 & $\begin{array}{l}\text { Jackson } \\
\text { ImmunoResearch }\end{array}$ & $\begin{array}{l}\text { Cat\# 715-175-150, } \\
\text { RRID:AB_2340819 }\end{array}$ \\
\hline Donkey anti guinea pig Alexa Cy5 & $\begin{array}{l}\text { Jackson } \\
\text { ImmunoResearch }\end{array}$ & $\begin{array}{l}\text { Cat\# 706-175-148, } \\
\text { RRID:AB_2340462 }\end{array}$ \\
\hline
\end{tabular}




\begin{tabular}{|c|c|c|}
\hline \multicolumn{3}{|c|}{ Chemicals } \\
\hline X-Gal & Roche & $\begin{array}{l}\text { 10745740001; CAS } \\
7240-90-6\end{array}$ \\
\hline DAPI & Sigma Aldrich & CAS 28718-90-3 \\
\hline \multicolumn{3}{|c|}{ Commercial Assays } \\
\hline Click-iT EdU & Thermofisher & C10340 \\
\hline \multicolumn{3}{|c|}{ Mouse Strains } \\
\hline Mouse: Shhtm1Ahk & $\begin{array}{l}\text { Gonzalez-Reyes L, et } \\
\text { al., } 2012\end{array}$ & MGI:5440762 \\
\hline Mouse: B6;129S6-Chat ${ }^{\mathrm{tm} 1(\mathrm{cre}) \text { Lowl/J }}$ & $\begin{array}{l}\text { The Jackson } \\
\text { Laboratory }\end{array}$ & JAX: 006410 \\
\hline Mouse: B6.Cg-Tg(Nes-cre) $1 \mathrm{~K} \ln / \mathrm{J}$ & $\begin{array}{l}\text { The Jackson } \\
\text { Laboratory }\end{array}$ & JAX: 003771 \\
\hline Mouse: Olig2 ${ }^{\text {tm1(cre)Tmj }}$ & $\begin{array}{l}\text { Dessaud E, et al., } \\
2007\end{array}$ & MGI:3774124 \\
\hline Mouse: Gt(ROSA)26Sortm4(ACTB-tdTomato,-EGFP)Luo/J & $\begin{array}{l}\text { The Jackson } \\
\text { Laboratory }\end{array}$ & JAX: 007576 \\
\hline
\end{tabular}




\section{References:}

Akazawa, C., H. Tsuzuki, Y. Nakamura, Y. Sasaki, K. Ohsaki, S. Nakamura, Y. Arakawa and S. Kohsaka (2004). "The upregulated expression of sonic hedgehog in motor neurons after rat facial nerve axotomy." J Neurosci 24(36): 7923-7930.

Al Oustah, A., C. Danesin, N. Khouri-Farah, M. A. Farreny, N. Escalas, P. Cochard, B. Glise and C. Soula (2014). "Dynamics of sonic hedgehog signaling in the ventral spinal cord are controlled by intrinsic changes in source cells requiring sulfatase 1." Development 141(6): 1392-1403.

Alaynick, W. A., T. M. Jessell and S. L. Pfaff (2011). "SnapShot: spinal cord development." Cell 146(1): 178-178 e171. Balaskas, N., A. Ribeiro, J. Panovska, E. Dessaud, N. Sasai, K. M. Page, J. Briscoe and V. Ribes (2012). "Gene regulatory logic for reading the Sonic Hedgehog signaling gradient in the vertebrate neural tube." Cell 148(1-2): 273-284.

Barkai, N. and D. Ben-Zvi (2009). "'Big frog, small frog'--maintaining proportions in embryonic development: delivered on 2 July 2008 at the 33rd FEBS Congress in Athens, Greece." FEBS J 276(5): 1196-1207.

Ben-Zvi, D. and N. Barkai (2010). "Scaling of morphogen gradients by an expansion-repression integral feedback control." Proc Natl Acad Sci U S A 107(15): 6924-6929.

Ben-Zvi, D., A. Fainsod, B. Z. Shilo and N. Barkai (2014). "Scaling of dorsal-ventral patterning in the Xenopus laevis embryo." Bioessays 36(2): 151-156.

Bergles, D. E. and W. D. Richardson (2015). "Oligodendrocyte Development and Plasticity." Cold Spring Harb Perspect Biol 8(2): a020453.

Beug, S. T., R. J. Parks, H. M. McBride and V. A. Wallace (2011). "Processing-dependent trafficking of Sonic hedgehog to the regulated secretory pathway in neurons." Mol Cell Neurosci 46(3): 583-596. Bjugn, R. and H. J. Gundersen (1993). "Estimate of the total number of neurons and glial and endothelial cells in the rat spinal cord by means of the optical disector." J Comp Neurol 328(3): 406-414. Briscoe, J. and J. Ericson (1999). "The specification of neuronal identity by graded Sonic Hedgehog signalling." Semin Cell Dev Biol 10(3): 353-362. Briscoe, J., A. Pierani, T. M. Jessell and J. Ericson (2000). "A homeodomain protein code specifies progenitor cell identity and neuronal fate in the ventral neural tube." Cell 101(4): 435-445. Charrier, J. B., F. Lapointe, N. M. Le Douarin and M. A. Teillet (2002). "Dual origin of the floor plate in the avian embryo." Development 129(20): 4785-4796. 
690

691

Cheung, D., C. Miles, M. Kreitman and J. Ma (2014). "Adaptation of the length scale and amplitude of the Bicoid gradient profile to achieve robust patterning in abnormally large Drosophila melanogaster embryos." Development 141(1): 124-135.

Cohen, M., A. Kicheva, A. Ribeiro, R. Blassberg, K. M. Page, C. P. Barnes and J. Briscoe (2015). "Ptch1 and Gli regulate Shh signalling dynamics via multiple mechanisms." Nat Commun 6: 6709.

Danesin, C., E. Agius, N. Escalas, X. Ai, C. Emerson, P. Cochard and C. Soula (2006). "Ventral neural progenitors switch toward an oligodendroglial fate in response to increased Sonic hedgehog (Shh) activity: involvement of Sulfatase 1 in modulating Shh signaling in the ventral spinal cord." J Neurosci 26(19): 5037-5048.

Danesin, C. and C. Soula (2017). "Moving the Shh Source over Time: What Impact on Neural Cell Diversification in the Developing Spinal Cord?" J Dev Biol 5(2).

Dasen, J. S. (2017). "Master or servant? emerging roles for motor neuron subtypes in the construction and evolution of locomotor circuits." Curr Opin Neurobiol 42: 25-32.

Dessaud, E., A. P. McMahon and J. Briscoe (2008). "Pattern formation in the vertebrate neural tube: a sonic hedgehog morphogen-regulated transcriptional network." Development 135(15): 2489-2503.

Dessaud, E., V. Ribes, N. Balaskas, L. L. Yang, A. Pierani, A. Kicheva, B. G. Novitch, J. Briscoe and N. Sasai (2010). "Dynamic assignment and maintenance of positional identity in the ventral neural tube by the morphogen sonic hedgehog." PLoS Biol 8(6): e1000382.

Dessaud, E., L. L. Yang, K. Hill, B. Cox, F. Ulloa, A. Ribeiro, A. Mynett, B. G. Novitch and J. Briscoe (2007). "Interpretation of the sonic hedgehog morphogen gradient by a temporal adaptation mechanism." Nature 450(7170): 717-720.

Dimou, L. and M. Simons (2017). "Diversity of oligodendrocytes and their progenitors." Curr Opin Neurobiol 47: 73-79.

Fu, H., Y. Qi, M. Tan, J. Cai, H. Takebayashi, M. Nakafuku, W. Richardson and M. Qiu (2002). "Dual origin of spinal oligodendrocyte progenitors and evidence for the cooperative role of Olig2 and Nkx2.2 in the control of oligodendrocyte differentiation." Development 129(3): 681-693.

Gonzalez-Reyes, L. E., M. Verbitsky, J. Blesa, V. Jackson-Lewis, D. Paredes, K. Tillack, S. Phani, E. R. Kramer, S. Przedborski and A. H. Kottmann (2012). "Sonic hedgehog maintains cellular and neurochemical homeostasis in the adult nigrostriatal circuit." Neuron 75(2): 306-319.

Gregor, T., W. Bialek, R. R. de Ruyter van Steveninck, D. W. Tank and E. F. Wieschaus (2005). "Diffusion and scaling during early embryonic pattern formation." Proc Natl Acad Sci U S A 102(51): 18403-18407. Hamaratoglu, F., A. M. de Lachapelle, G. Pyrowolakis, S. Bergmann and M. Affolter (2011). "Dpp signaling activity requires Pentagone to scale with tissue size in the growing Drosophila wing imaginal disc." PLoS Biol 9(10): e1001182.

Houchmandzadeh, B., E. Wieschaus and S. Leibler (2005). "Precise domain specification in the developing Drosophila embryo." Phys Rev E Stat Nonlin Soft Matter Phys 72(6 Pt 1): 061920. Howard, M. and P. R. ten Wolde (2005). "Finding the center reliably: robust patterns of developmental gene expression." Phys Rev Lett 95(20): 208103.

Huang, Y. and D. Umulis (2018). "Mechanisms and Measurements of Scale Invariance of Morphogen Gradients." Methods Mol Biol 1863: 251-262.

Jessell, T. M. (2000). "Neuronal specification in the spinal cord: inductive signals and transcriptional codes." Nat Rev Genet 1(1): 20-29.

Kicheva, A., T. Bollenbach, A. Ribeiro, H. P. Valle, R. Lovell-Badge, V. Episkopou and J. Briscoe (2014). "Coordination of progenitor specification and growth in mouse and chick spinal cord." Science 345(6204): 1254927.

Kicheva, A. and J. Briscoe (2015). "Developmental Pattern Formation in Phases." Trends Cell Biol 25(10): 579-591.

Lander, A. D. (2007). "Morpheus unbound: reimagining the morphogen gradient." Cell 128(2): 245-256. 
726

727
McHale, P., W. J. Rappel and H. Levine (2006). "Embryonic pattern scaling achieved by oppositely directed morphogen gradients." Phys Biol 3(2): 107-120. Mizuguchi, R., M. Sugimori, H. Takebayashi, H. Kosako, M. Nagao, S. Yoshida, Y. Nabeshima, K. Shimamura and M. Nakafuku (2001). "Combinatorial roles of olig2 and neurogenin2 in the coordinated induction of pan-neuronal and subtype-specific properties of motoneurons." Neuron 31(5): 757-771. Novitch, B. G., A. I. Chen and T. M. Jessell (2001). "Coordinate regulation of motor neuron subtype identity and pan-neuronal properties by the bHLH repressor Olig2." Neuron 31(5): 773-789. Oppenheim, R. W., S. Homma, E. Marti, D. Prevette, S. Wang, H. Yaginuma and A. P. McMahon (1999). "Modulation of early but not later stages of programmed cell death in embryonic avian spinal cord by sonic hedgehog." Mol Cell Neurosci 13(5): 348-361. Osterstock, G., B. Le Bras, K. H. Arulkandarajah, H. Le Corronc, A. Czarnecki, C. Mouffle, E. Bullier, P. Legendre and J. M. Mangin (2018). "Axoglial synapses are formed onto pioneer oligodendrocyte precursor cells at the onset of spinal cord gliogenesis." Glia.

Park, H. C., J. Shin and B. Appel (2004). "Spatial and temporal regulation of ventral spinal cord precursor specification by Hedgehog signaling." Development 131(23): 5959-5969.

Ravanelli, A. M. and B. Appel (2015). "Motor neurons and oligodendrocytes arise from distinct cell lineages by progenitor recruitment." Genes Dev 29(23): 2504-2515.

Ravanelli, A. M., C. A. Kearns, R. K. Powers, Y. Wang, J. H. Hines, M. J. Donaldson and B. Appel (2018). "Sequential specification of oligodendrocyte lineage cells by distinct levels of Hedgehog and Notch signaling." Dev Biol 444(2): 93-106.

Touahri, Y., N. Escalas, B. Benazeraf, P. Cochard, C. Danesin and C. Soula (2012). "Sulfatase 1 promotes the motor neuron-to-oligodendrocyte fate switch by activating Shh signaling in Olig2 progenitors of the embryonic ventral spinal cord." J Neurosci 32(50): 18018-18034.

Traiffort, E., M. Zakaria, Y. Laouarem and J. Ferent (2016). "Hedgehog: A Key Signaling in the Development of the Oligodendrocyte Lineage." J Dev Biol 4(3).

Umulis, D. M. and H. G. Othmer (2013). "Mechanisms of scaling in pattern formation." Development 140(24): 4830-4843.

Uygur, A., J. Young, T. R. Huycke, M. Koska, J. Briscoe and C. J. Tabin (2016). "Scaling Pattern to Variations in Size during Development of the Vertebrate Neural Tube." Dev Cell 37(2): 127-135. Yu, K., S. McGlynn and M. P. Matise (2013). "Floor plate-derived sonic hedgehog regulates glial and ependymal cell fates in the developing spinal cord." Development 140(7): 1594-1604. 
E12.5
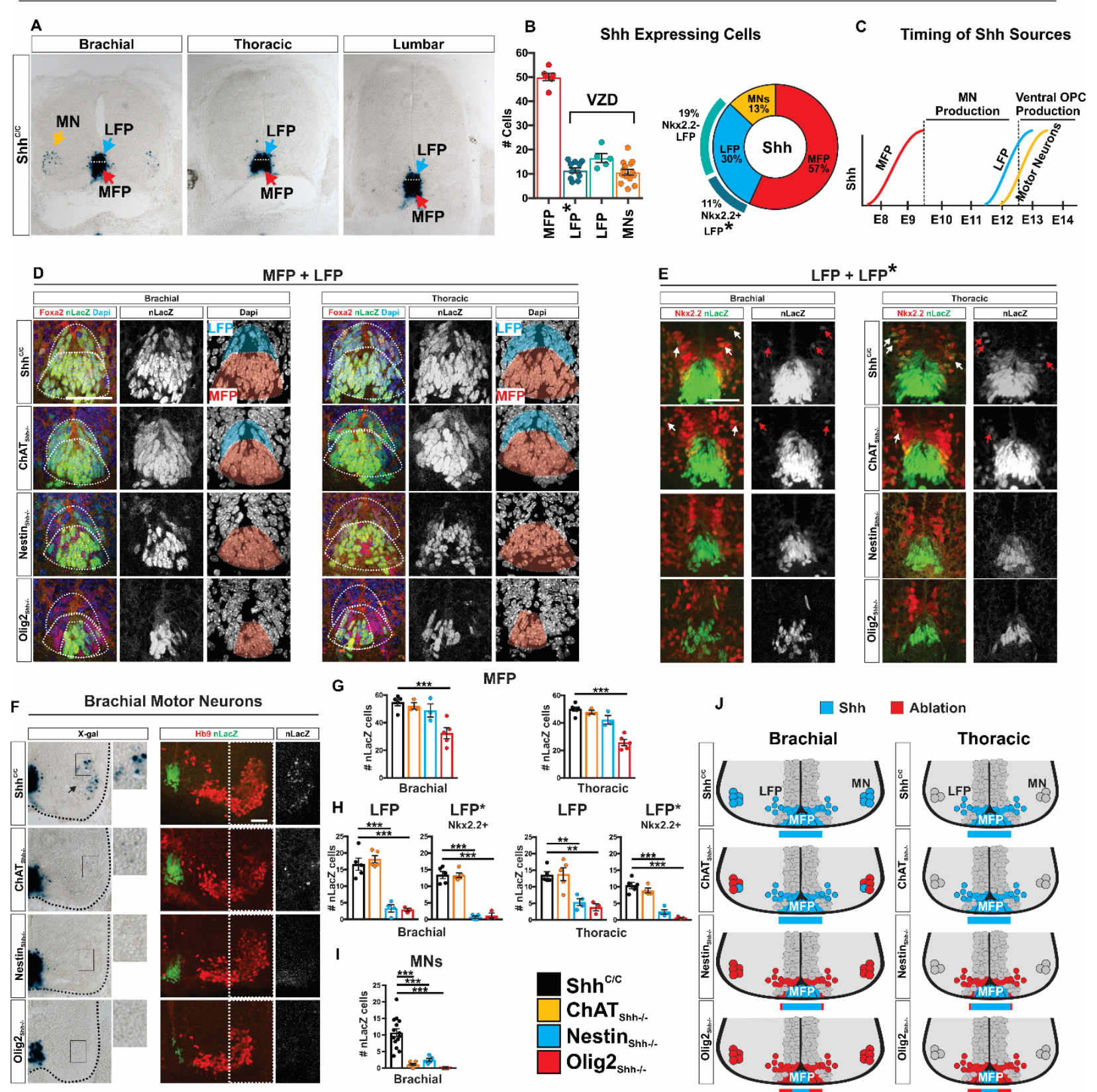

J $\square$ Shh ablation
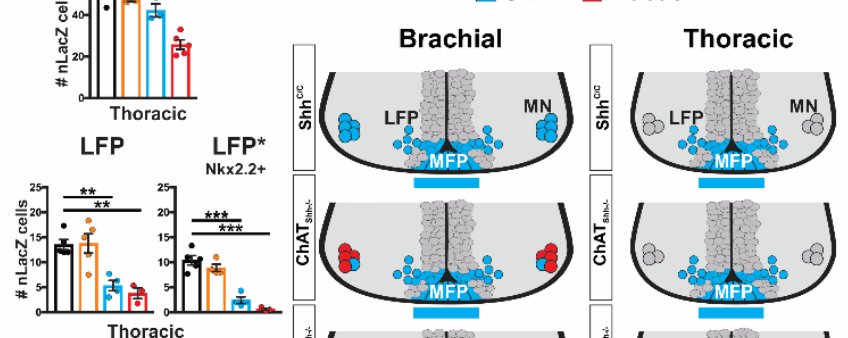

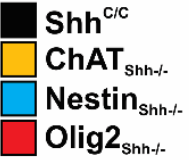
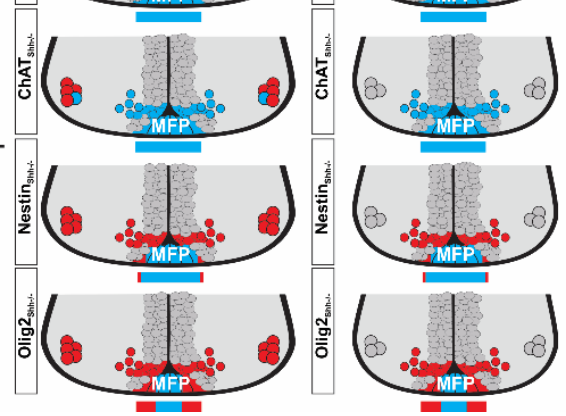

Fig. 1. Shh expression and ablation strategy in the ventral spinal cord at E12.5. 
Fig. 1. Shh expression and ablation strategy in the ventral spinal cord at E12.5.

(A) X-gal staining of Shh expressing cells of E12.5 control Shh ${ }^{\mathrm{ClC}}$ spinal cord sections. Three sources identified: Medial floor plate (MFP), lateral floor plate (LFP), and motor neurons (MN).

(B) Numbers of nLacZ expressing cells in MFP (FoxA2+) n=6, LFP (FoxA2+ Nkx2.2-) $n=5, L^{*} P^{*}(N k x 2.2+) n=11$, and among MNs $(H b 9+) n=14$. Ventricular zone derived (VDZ): LFP, LFP*, and MNs. Breakdown percentages of each Shh source relative to total. Means \pm SEM are shown.

(C) Overlap in MN and ventral OPC generation from pMN domain with the timing of Shh expression from all sources.

(D) Immunostaining for $\mathrm{nLacZ}$ and FoxA2 on brachial and thoracic segments. Identification of MFP (FoxA2+ nLacZ+) and LFP (FoxA2+ nLacZ+). LFP cells are identified as dorsal to MFP cells, oriented in tangent to MFP, and expressing lower levels of $n L a c Z$.

(E) Immunostaining for $\mathrm{nLacZ}$ and Nkx2.2 on brachial and thoracic segments. Identification of LFP (Nkx2.2- nLacZ+) and LFP* (Nkx2.2+ nLacZ+). Arrows point to migrating LFP* Nkx2.2+ nLacZ+ cells.

(F) X-gal staining and immunostaining for $\mathrm{nLacZ}$ and $\mathrm{Hb9}$ on brachial segments.

(G) Quantification of MFP nLacZ recombination at brachial and thoracic segments for each Shh source per genotype. Brachial and thoracic segments Shh ${ }^{\mathrm{ClC}} \mathrm{n}=5, \mathrm{ChAT} \mathrm{shh}^{-1-}$ $n=3$, Nestinshn ${ }^{-1-} n=3$, Olig2 $\mathrm{shn}^{-1-} n=5$. Means $\pm S E M$ are shown. One-way ANOVA, Dunnett's multiple comparison post hoc test. $* p<0.05, * * p<0.01, * * * p<0.001$.

(H) Quantification of LFP and LFP* nLacZ recombination at brachial and thoracic segments for each Shh source per genotype. Brachial and thoracic segments Shh ${ }^{\mathrm{C} / \mathrm{C}}$ $n=5$, ChAT shh ${ }^{-1-} n=4-5$, Nestinshh ${ }^{-/-} n=4$, Olig2 $\mathrm{Shn}^{-/-} \mathrm{n}=3$. Means \pm SEM are shown. Oneway ANOVA, Dunnett's multiple comparison post hoc test. $* p<0.05, * * p<0.01$, $* * * \mathrm{p}<0.001$.

(I) Quantification of $n L a c Z$ recombination in brachial MNs. Shh ${ }^{\mathrm{C} / \mathrm{C}} n=14, \mathrm{ChAT}_{\mathrm{Shh}^{-1}} n=8$, Nestin $\mathrm{Shh}^{-/-} n=5$, Olig2 $\mathrm{Shn}^{-/-} n=5$. Means \pm SEM are shown. One-way ANOVA, Dunnett's multiple comparison post hoc test. $* p<0.05, * * p<0.01, * * * p<0.001$.

(J) Schematic of Shh expressing cells at E12.5 brachial and thoracic segments and strategy of Cre ablation for each genotype. Scale bars, $50 \mu \mathrm{m}$. 


\section{E10.5}

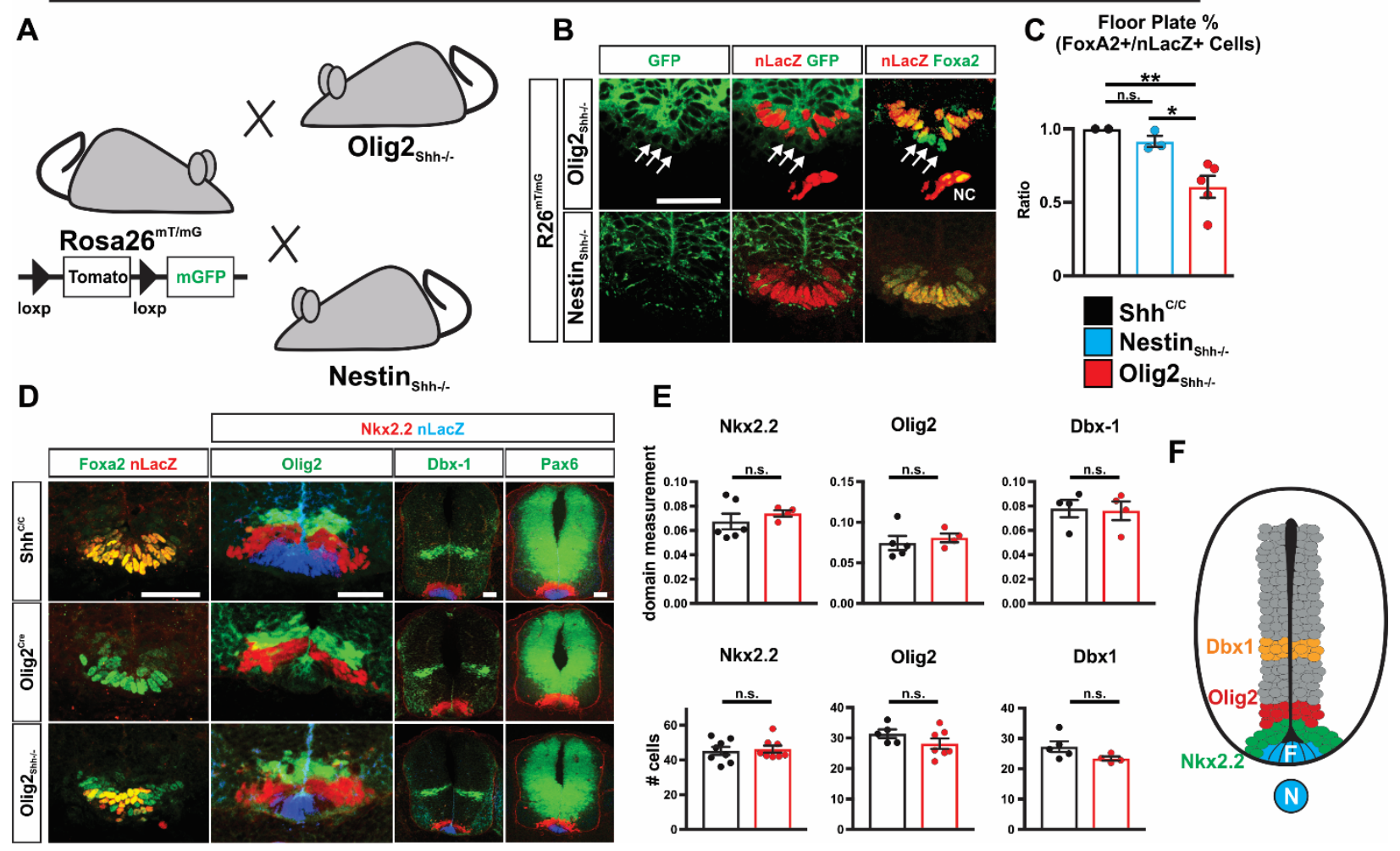

Fig. 2. Early spinal cord patterning is unaffected in Olig2 $\mathrm{shh}^{-1-}$.

(A) Detection of Cre activity in Olig2 $\mathrm{Shh}^{-/-}$and Nestinshh ${ }^{-/-}$mutants at E10.5 using the conditional R26mT/mG allele.

(B) GFP co-labeling of Cre activity in addition to a loss of nLacZ from Foxa2+ cells demonstrates Shh ablation in MFP of Olig2 $\mathrm{Shh}^{-/-}$but not Nestin $\mathrm{Shh}^{-/-}$embryos. Arrows indicate MFP FoxA2+ cells that have lost nLacZ expression. NC, notochord.

(C) Quantification of recombination frequency of the ratio of Foxa2+ nLacZ+ double positive cells. Shh ${ }^{\mathrm{C} / \mathrm{C}} \mathrm{n}=2$, Nestin $\operatorname{shn}^{-/-} \mathrm{n}=3$, Olig2 $\mathrm{Shh}^{-/-} \mathrm{n}=5$. Means \pm SEM are shown. One-way ANOVA, Tukey post hoc test. $* \mathrm{p}<0.05, * * \mathrm{p}<0.01$.

(D) Immunostaining of Shh-sensitive domains, Olig2, Nkx2.2, Dbx1, and Pax6 are unaffected at E10.5 in Olig2 $\mathrm{Shh}^{-/-}$, despite MFP recombination.

(E) Quantification of relative domain sizes and numbers of Nkx2.2, Olig2, Dbx1. Domain measurement Shh ${ }^{\mathrm{C} / \mathrm{C}} \mathrm{n}=4-6$, Olig2 $\mathrm{Shh}^{-1-} \mathrm{n}=4$. Means \pm SEM are shown. Cell counts $\mathrm{Shh}^{\mathrm{C} / \mathrm{C}} \mathrm{n}=5-8$, Olig2 $\mathrm{Shh}^{-/-} \mathrm{n}=4-8$. Data were analyzed by Student's t test. $* \mathrm{p}<0.05$, $* * \mathrm{p}<0.01$.

(F) Scheme highlighting position of p3 (Nkx2.2), p0 (Dbx-1), and pMN (Olig2) domains relative to the MFP at E10.5. 


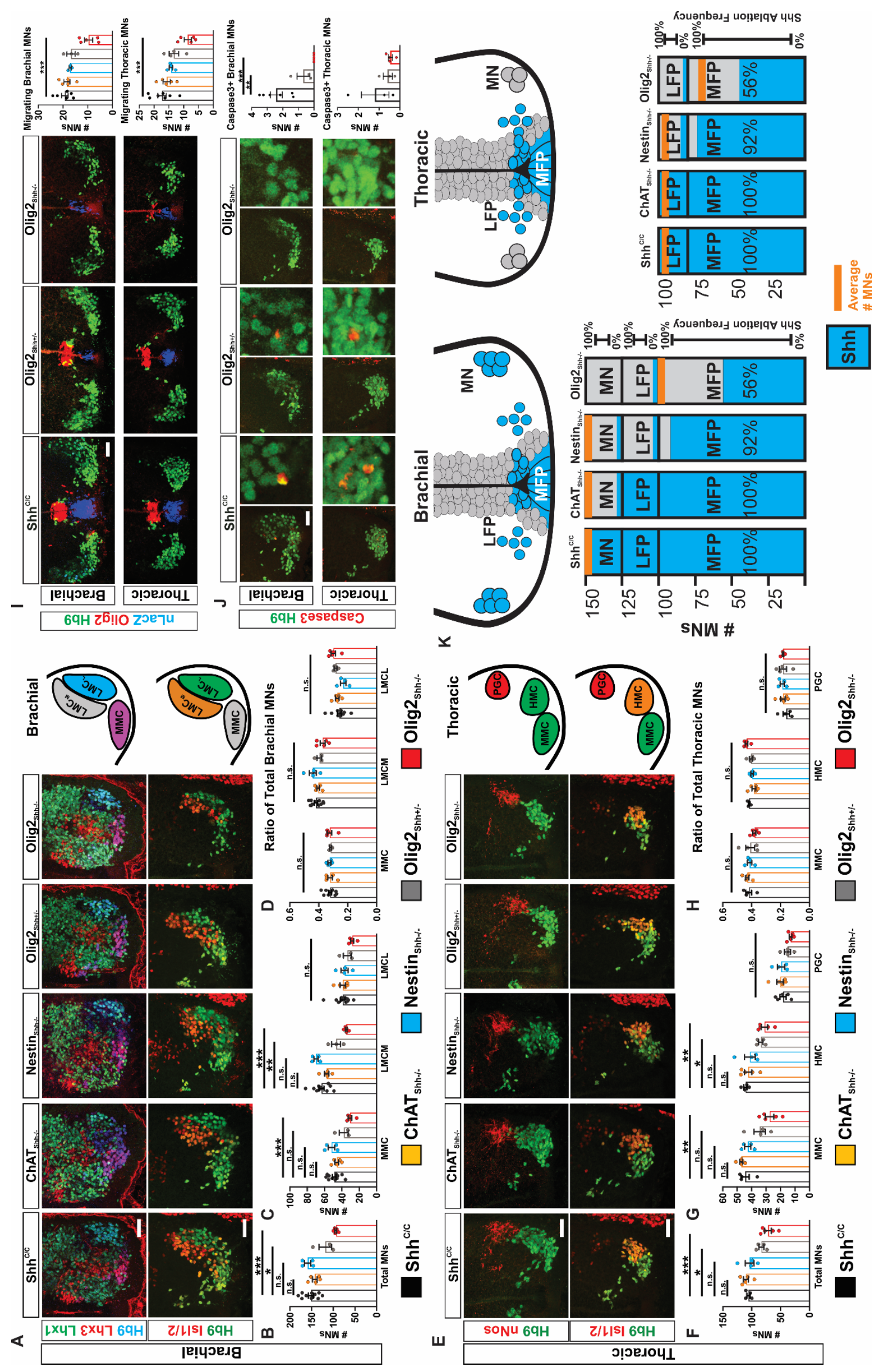


Fig. 3. Shh signaling from MFP, but not VZD influences MN generation.

(A) E12.5 brachial sections immunostained with $\mathrm{Hb9}$, Lhx3, and Lhx1 to distinguish MMC and LMCL columns, and Hb9 and IsI/1/2 to distinguish LMCM and LMCL columns.

(B) Quantification of total brachial MNs. Shh ${ }^{\mathrm{C} / \mathrm{C}} \mathrm{n}=11, \mathrm{ChATShh}^{-1-} \mathrm{n}=5$, Nestinshh ${ }^{-1-} n=4$, Olig2 $\mathrm{Shh}^{+/-} \mathrm{n}=3$, Olig2 $\mathrm{shh}^{-1-} \mathrm{n}=5$. Means \pm SEM are shown. One-way ANOVA, Dunnett's multiple comparison post hoc test. $* \mathrm{p}<0.05, * * \mathrm{p}<0.01, * * * \mathrm{p}<0.001$.

(C) Quantification of total numbers of MMC, LMCM, and LMCL MNs. Means \pm SEM are shown. One-way ANOVA, Dunnett's multiple comparison post hoc test. $* p<0.05$, $* * \mathrm{p}<0.01, * * * \mathrm{p}<0.001$.

(D) Ratio of each motor column to total brachial MNs. Means \pm SEM are shown. Oneway ANOVA, Dunnett's multiple comparison post hoc test. NS, not significant, $P>0.5$.

(E) E12.5 thoracic sections immunostained with $\mathrm{Hb} 9$ and nNos to distinguish $\mathrm{MMC}$ and $\mathrm{HMC}$ from PGC column, and $\mathrm{Hb} 9$ and IsI $1 / 2$ to distinguish MMC and HMC columns.

(F) Quantification of total thoracic MNs. Shh ${ }^{C / C} n=4-5$, ChAT $\operatorname{shh}^{-/-} n=5$, Nestinshn ${ }^{-/-} n=4$, Olig2 $\mathrm{Shh}^{+/-} \mathrm{n}=4$, Olig2 $\mathrm{Shn}^{-1-} \mathrm{n}=5$. Means \pm SEM are shown. One-way ANOVA, Dunnett's multiple comparison post hoc test. $* \mathrm{p}<0.05, * * \mathrm{p}<0.01, * * * \mathrm{p}<0.001$.

(G) Quantification of total numbers of MMC, HMC, and PGC MNs. Means \pm SEM are shown. One-way ANOVA, Dunnett's multiple comparison post hoc test. $* p<0.05$, $* * p<0.01, * * * p<0.001$.

(H) Ratio of each column to total thoracic MNs. Means \pm SEM are shown. One-way ANOVA, Dunnett's multiple comparison post hoc test. NS, not significant, $P>0.5$.

(I) Immunostaining and quantification of late born migrating $\mathrm{Hb9}+\mathrm{MNs}$ at E12.5 brachial

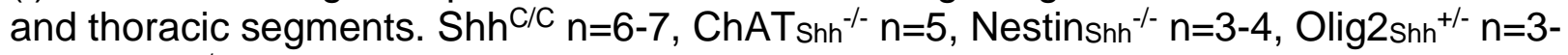
4 , Olig2 $\mathrm{shh}^{-1-} \mathrm{n}=5$. Means \pm SEM are shown. One-way ANOVA, Dunnett's multiple comparison post hoc test. $* * * p<0.001$.

(J) Immunostaining and quantification of $\mathrm{Hb9}+$ Caspase $3+$ apoptotic MNs at E12.5 brachial and thoracic segments. Shh ${ }^{C / C} n=3-6$, Olig2 $\operatorname{shn}^{+/-} n=3$, Olig2 $\operatorname{shn}^{-1-} n=4-5$. Means \pm SEM are shown. One-way ANOVA, Dunnett's multiple comparison post hoc test. $* * p<0.01, * * * p<0.001$.

(K) Schematic representing Shh ablation within the genotypes and associated numbers of average MNs for brachial and thoracic sections. Scale bars, $50 \mu \mathrm{m}$. 
ш
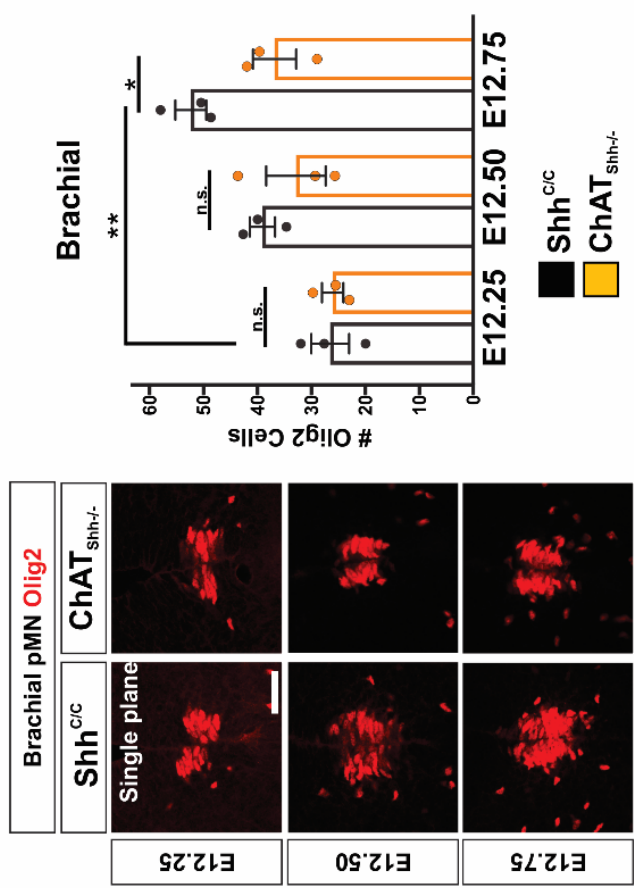

口
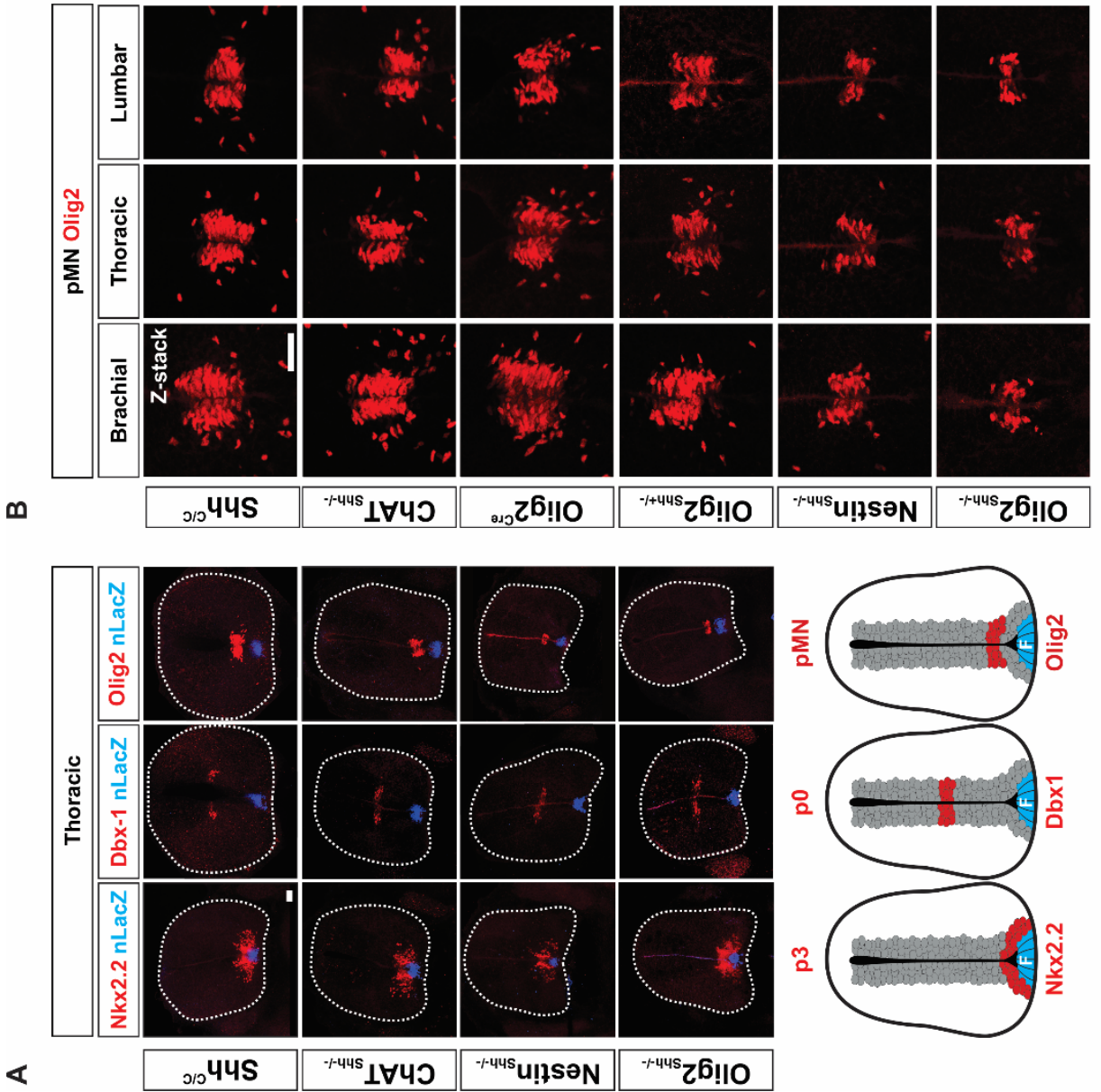

ᄂ

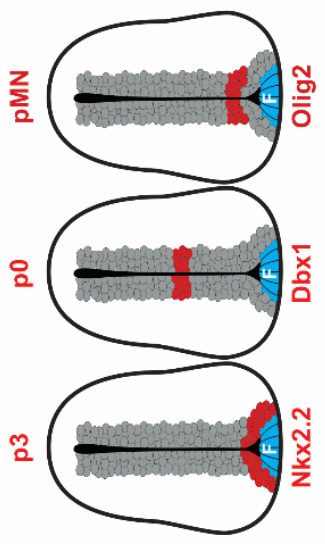

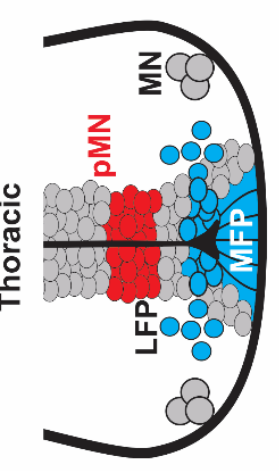
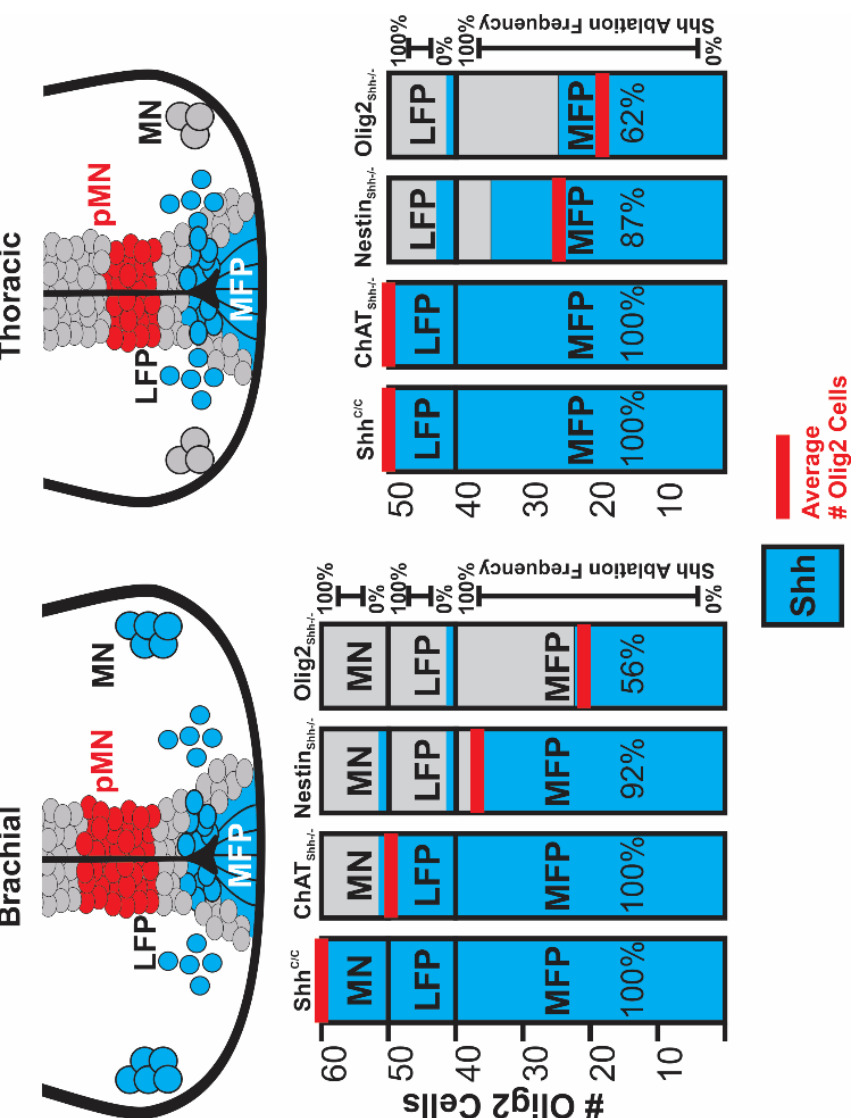

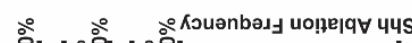
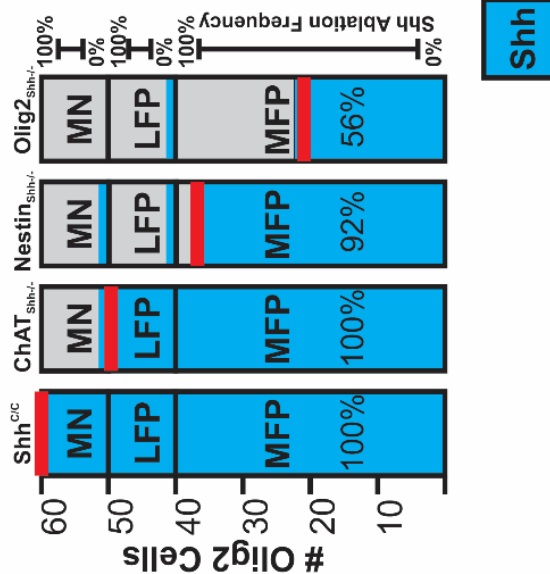

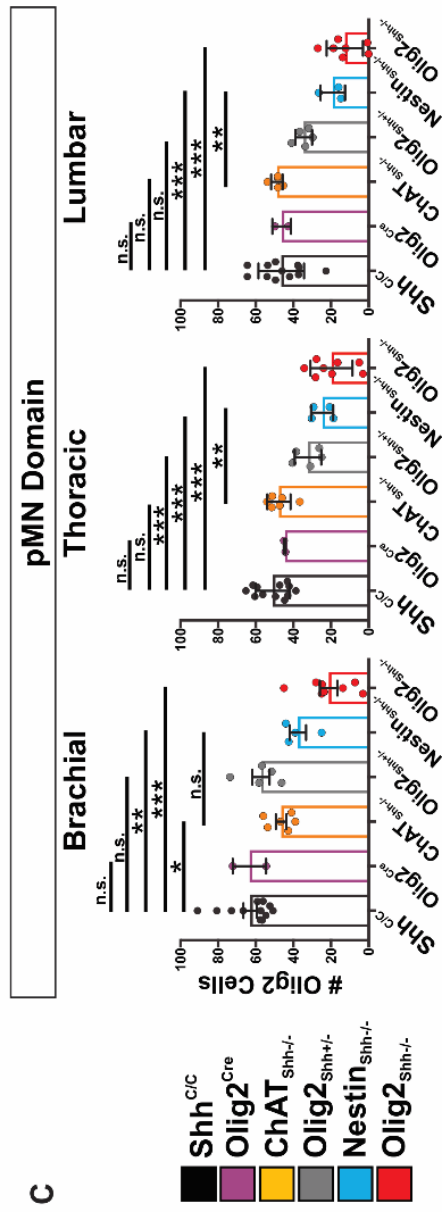


Fig. 4. Shh from VZD in addition to MFP is critical for pMN domain maintenance in a spinal level specific manner.

(A) Immunostaining of $\mathrm{nLacZ}$ with Nkx2.2, Dbx-1, and Olig2 on E12.5 thoracic sections. (B) Immunostaining for Olig2 in the pMN domain along the AP axis on brachial, thoracic, and lumbar sections for Shh ${ }^{\mathrm{Cl}}$, ChAT $\mathrm{Shn}^{-1-}$, Nestinshn ${ }^{-1-}$, Olig2-Cre, Olig2 $\mathrm{Shh}^{+1-}$, and Olig2 $\mathrm{Shh}^{-1-}$.

(C) Quantification of numbers of Olig2 cells in the pMN domain for brachial, thoracic, and lumbar sections. Means \pm SEM are shown. Shh ${ }^{\mathrm{ClC}} \mathrm{n}=12$, Olig2-Cre $n=2, \mathrm{ChAT}_{\mathrm{Sh}^{-1-}}$ $\mathrm{n}=6$, Olig2 $\mathrm{Shn}^{+/-} \mathrm{n}=5$, Nestin $\mathrm{Shn}^{-1-} \mathrm{n}=4$, Olig2 $\mathrm{Shh}^{-1-} \mathrm{n}=8$. One-way ANOVA, Dunnett's or Tukey's multiple comparison post hoc test. $* p<0.05, * * p<0.01, * * * p<0.001$.

(D) Expansion of pMN domain at onset of gliogenesis at brachial segments between E12.25-E12.75 is reduced in ChAT $\mathrm{Shn}^{-1-}$.

(E) Quantification of Olig2 cells in the pMN domain on brachial segments. Means \pm SEM are shown. E12.25 Shh ${ }^{\mathrm{ClC}} \mathrm{n}=3$, ChAT $\mathrm{Sh}^{-/-} \mathrm{n}=3, \mathrm{E} 12.50 \mathrm{Shh}^{\mathrm{ClC}} \mathrm{n}=3, \mathrm{ChAT}_{\mathrm{Shh}^{-/-}} \mathrm{n}=3$,

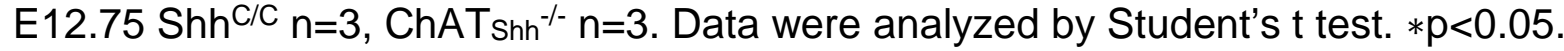

(F) Schematic representing Shh ablation within the genotypes and associated numbers of average pMN Olig2 cells for brachial and thoracic sections. Blue columns indicate percent of Shh expressing cells normalized to Shh ${ }^{\mathrm{C} / \mathrm{C}}$ controls for MFP, LFP, and MNs. Grey areas indicate Cre ablation. Red bars indicate average numbers of Olig2 cells within the pMN. Scale bars, $50 \mu \mathrm{m}$. 
A

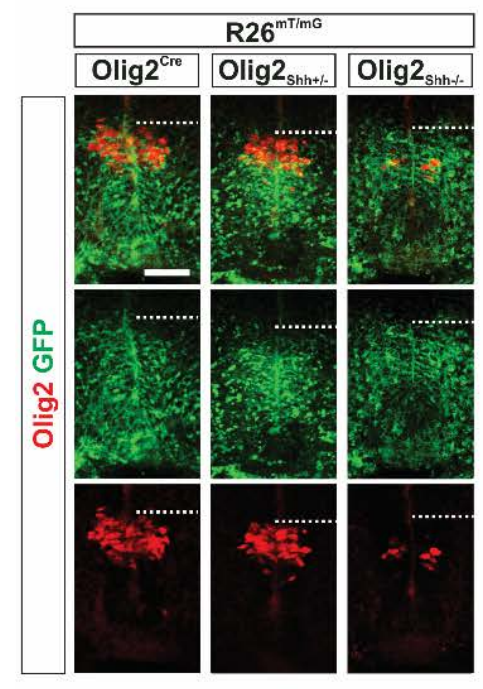

B

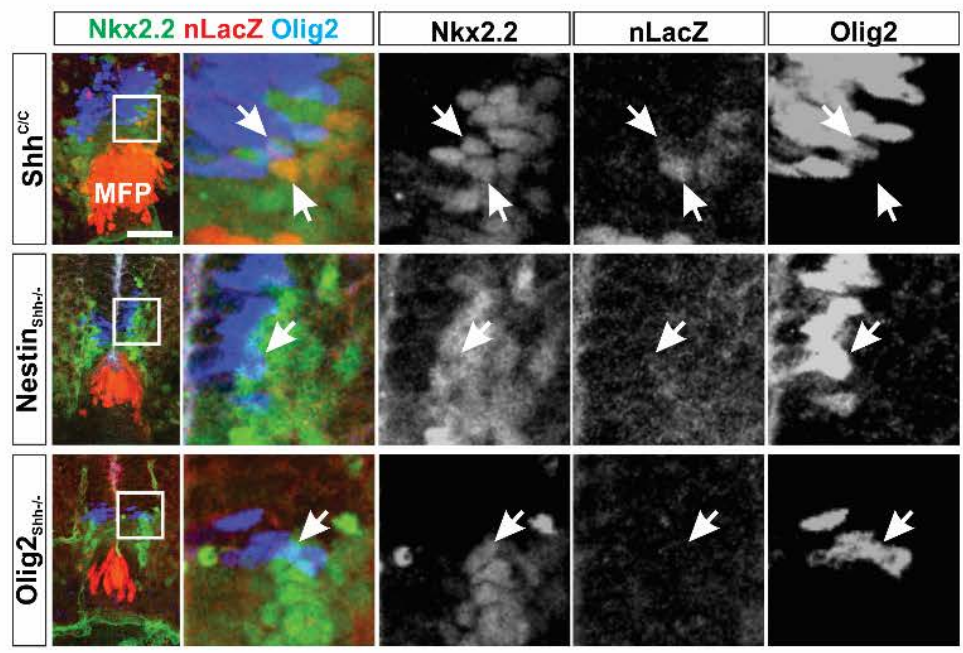

C

E12.5

Thoracic pMN

Olig2+ Nkx2.2+

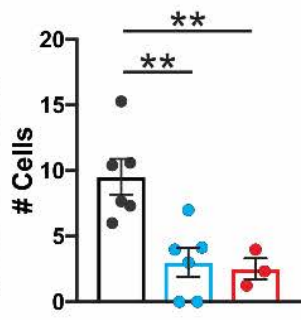

Shh $^{\mathrm{c} / \mathrm{C}}$
Nestin $_{\text {shh-l- }}$
Olig2 $_{\text {Shh-/. }}$

Fig. 5. pMNolig2+ expression and $\mathrm{p}^{*}$ domain formation requires Shh from MFP and VZD during onset of gliogenesis.

(A) E12.5 Lineage tracing reveals correct establishment of the pMN in Olig2 $\mathrm{Shh}^{-1-}$ as indicated by dorsal boundary of R26mT/mG expression, however failure of maintenance of Olig2 in pMN as detected by immunolabeling. Scale bars, $50 \mu \mathrm{m}$.

(B) $p^{*}$ domain is found in contact with LFP* in Shh ${ }^{\text {C/C }}$ controls but not in Nestinshh ${ }^{-1-}$ and Olig2 $\mathrm{Shn}^{-/-}$as identified by immunolabeling of Olig2+ Nkx2.2 ( $\left.\mathrm{p}^{\star}\right)$ and $\mathrm{nLacZ}+\mathrm{Nkx2.2+}$ $\left(\mathrm{LFP}^{\star}\right)$.

(C) Quantification of $\mathrm{p}^{*}$ domain in Shh ${ }^{\mathrm{C} / \mathrm{C}}$, Nestin $\mathrm{Shh}^{-1 /}$, and Olig2 $\mathrm{Shh}^{-1-}$. Means $\pm \mathrm{SEM}$ are shown. ShhC/C $n=6$, Nestin $\operatorname{shn}^{--} n=6$, Olig2 $\operatorname{shn}^{-/-} n=3$. One-way ANOVA, Dunnett's multiple comparison post hoc test. $* * p<0.01$. 

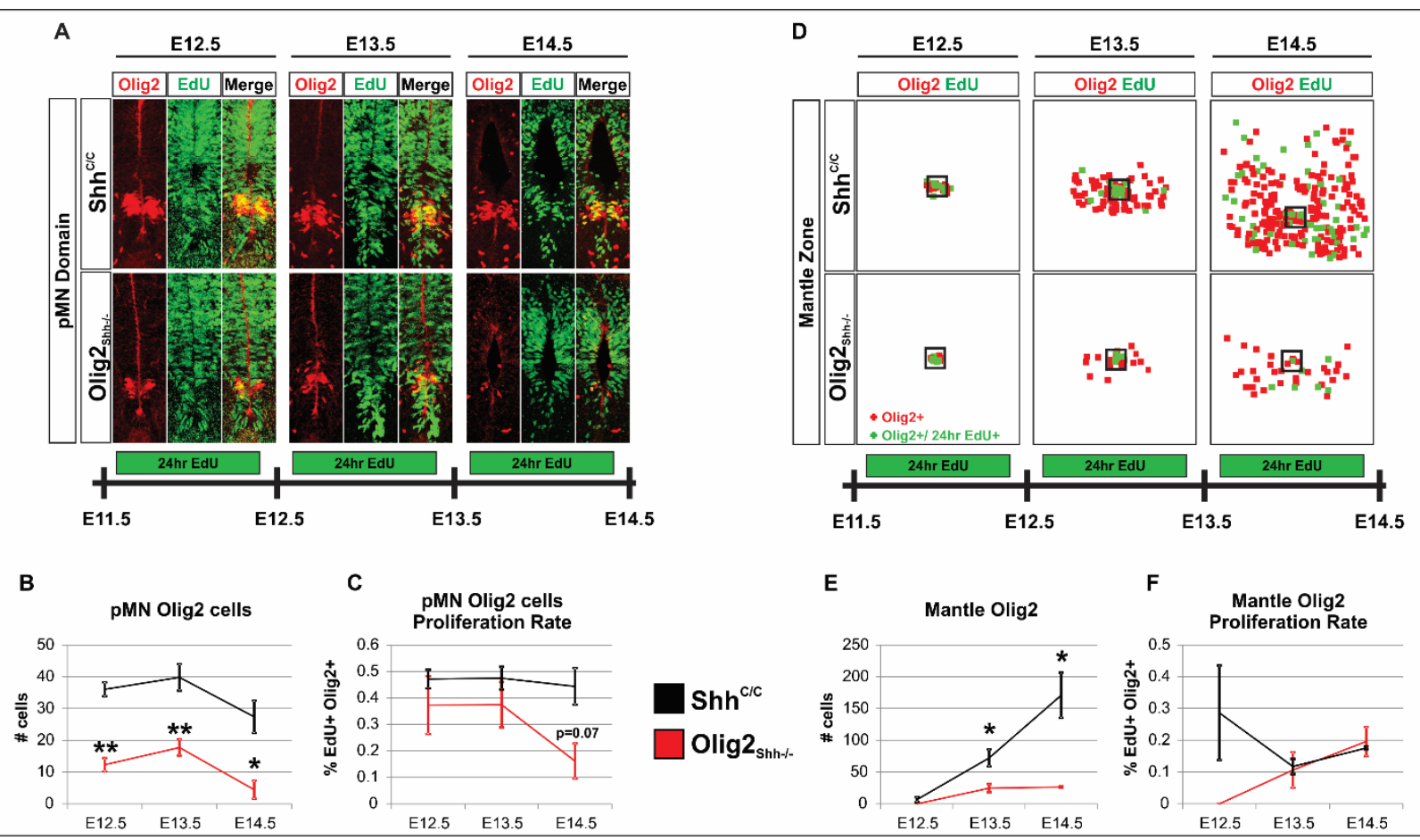

Fig. 6. Exhaustion of pMNolig2+ cells results in diminished OPC production.

(A) pMN domain proliferation in lumbar sections labeled by EdU incorporation in $24 \mathrm{hr}$ intervals for E12.5- E14.5 in ShhC/C and Olig2 $\mathrm{Shh}^{-1-}$.

(B) Total Olig2 cells in pMN at E12.5-E14.5. Means \pm SEM are shown. Shh ${ }^{\mathrm{C} / \mathrm{C}} \mathrm{n}=3-4$, Olig2 $\mathrm{Shh}^{-1-} \mathrm{n}=3-4$. Data were analyzed by Student's $\mathrm{t}$ test. $* \mathrm{p}<0.05, * * \mathrm{p}<0.01$.

(C) Proliferation rate of Olig2 cells in pMN E12.5, E13.5, and E14.5. Means \pm SEM are shown. Shh ${ }^{C / C} n=3-4$, Olig2 $\operatorname{shn}^{-1-} n=3-4$. Data were analyzed by Student's $t$ test.

(D) Tracing of migrating Olig2 cells on representative lumbar sections with proliferation labeled by EdU incorporation in 24hr intervals between E12.5- E14.5. Box indicates pMN domain, Olig2+ cells in the mantle zone (red), Olig2+ EdU+ cells (green).

(E) Total Olig2 cells in mantle zone at E12.5, E13.5, and E14.5. Olig2 cell numbers in Olig2 $\mathrm{Shh}^{-1-}$ mantle remain reduced. Means \pm SEM are shown. Shh ${ }^{\mathrm{Cl}} \mathrm{n}=3-4$, Olig2 $\mathrm{Shh}^{-1-}$ $\mathrm{n}=3-4$. Data were analyzed by Student's $\mathrm{t}$ test. $* \mathrm{p}<0.05$.

(F) Proliferation rate of Olig2 cells in mantle zone at E12.5, E13.5, and E14.5. Olig2 cells that have migrated out of the $\mathrm{pMN}$ in Olig2 $\mathrm{Shn}^{-1-}$ mutants proliferate at the same rate as controls. Means \pm SEM are shown. ShhC/C $n=3-4$, Olig2 shn $^{-1-} n=3-4$. 
A

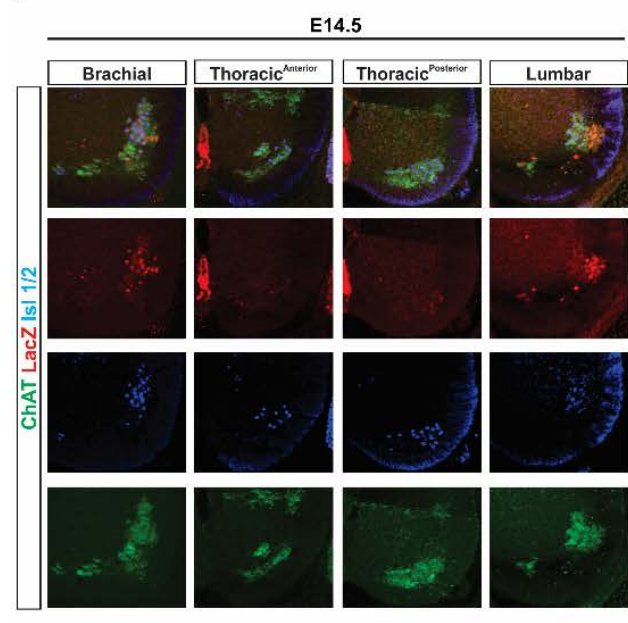

c

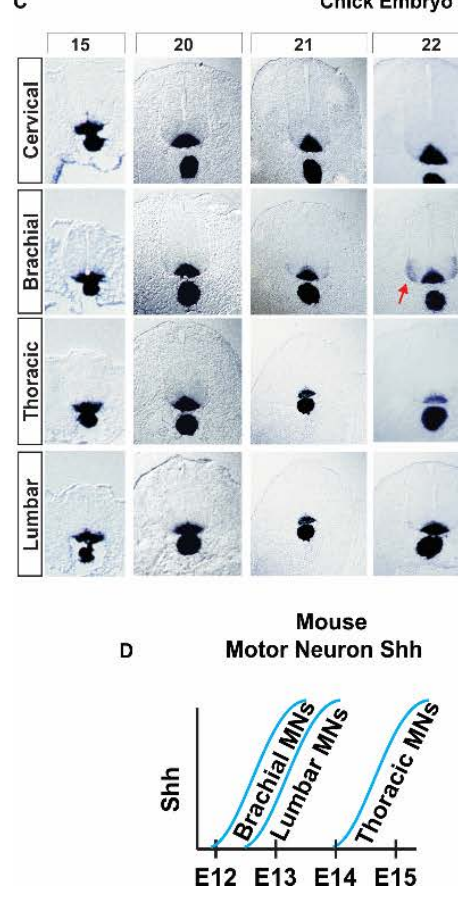

B

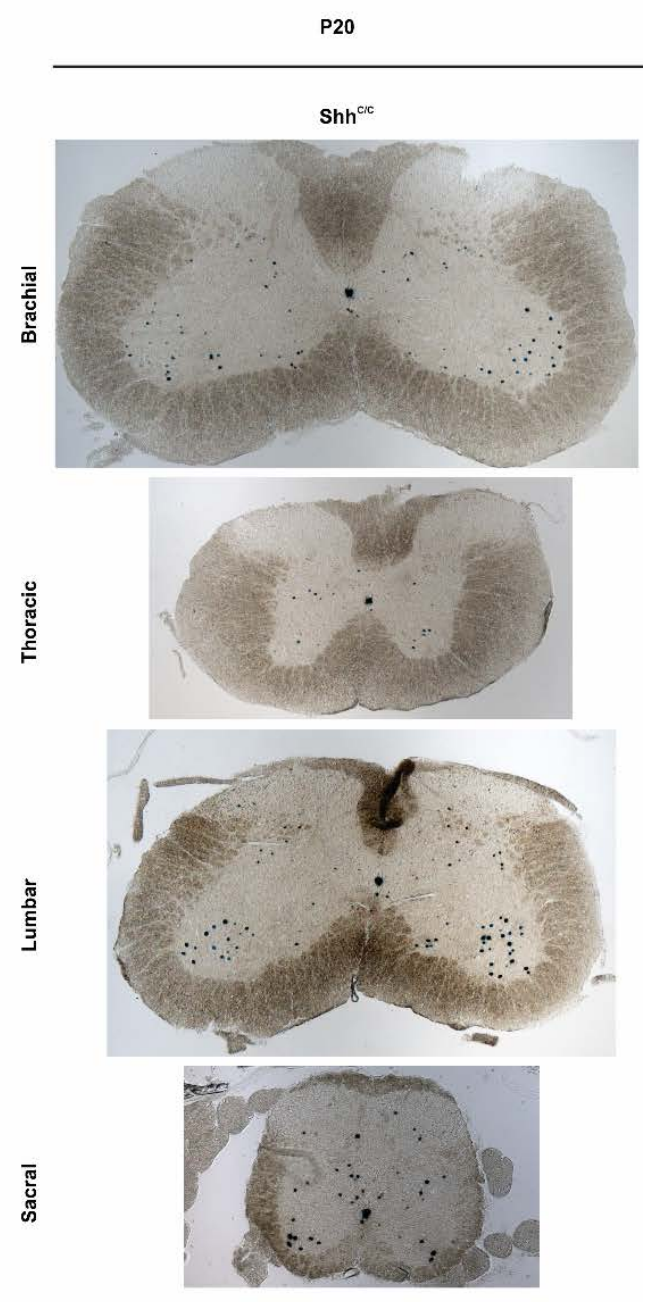

Fig. S1. Shh expression in MNs.

(A) Shh expression by MNs along AP axis at E14.5. Immunostaining colocalization of nLacZ with MN markers IsI1/2 and ChAT. Revealing that thoracic MNs express Shh much later than brachial and lumbar.

(B) X-gal staining revealing Shh expression pattern throughout AP axis of P20 control Shh ${ }^{\mathrm{C} / \mathrm{C}}$ spinal cords at brachial, thoracic, lumbar, and sacral segments.

(C) In situ hybridization for Shh in developing chick neural tube demonstrating comparable timing and pattern of Shh expression by MNs as in mouse.

(D and E) Timeline of Shh expression by MNs in (D) mouse and (E) chick. 
A
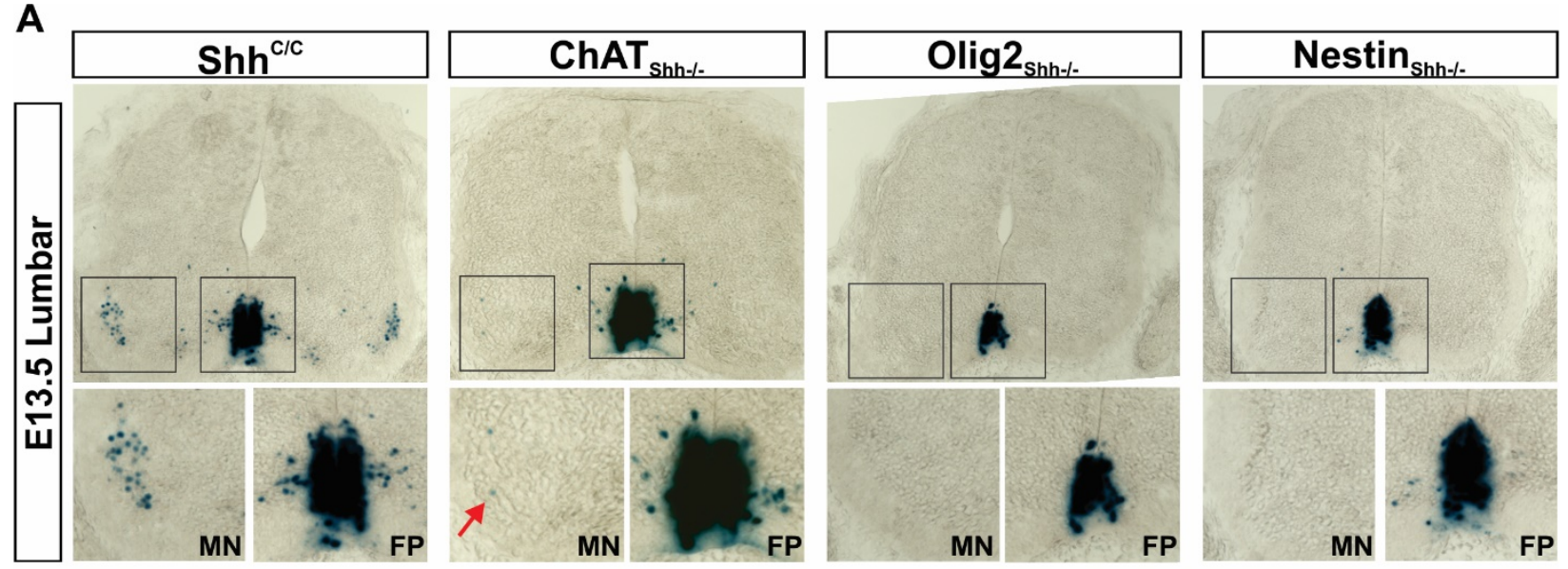

B
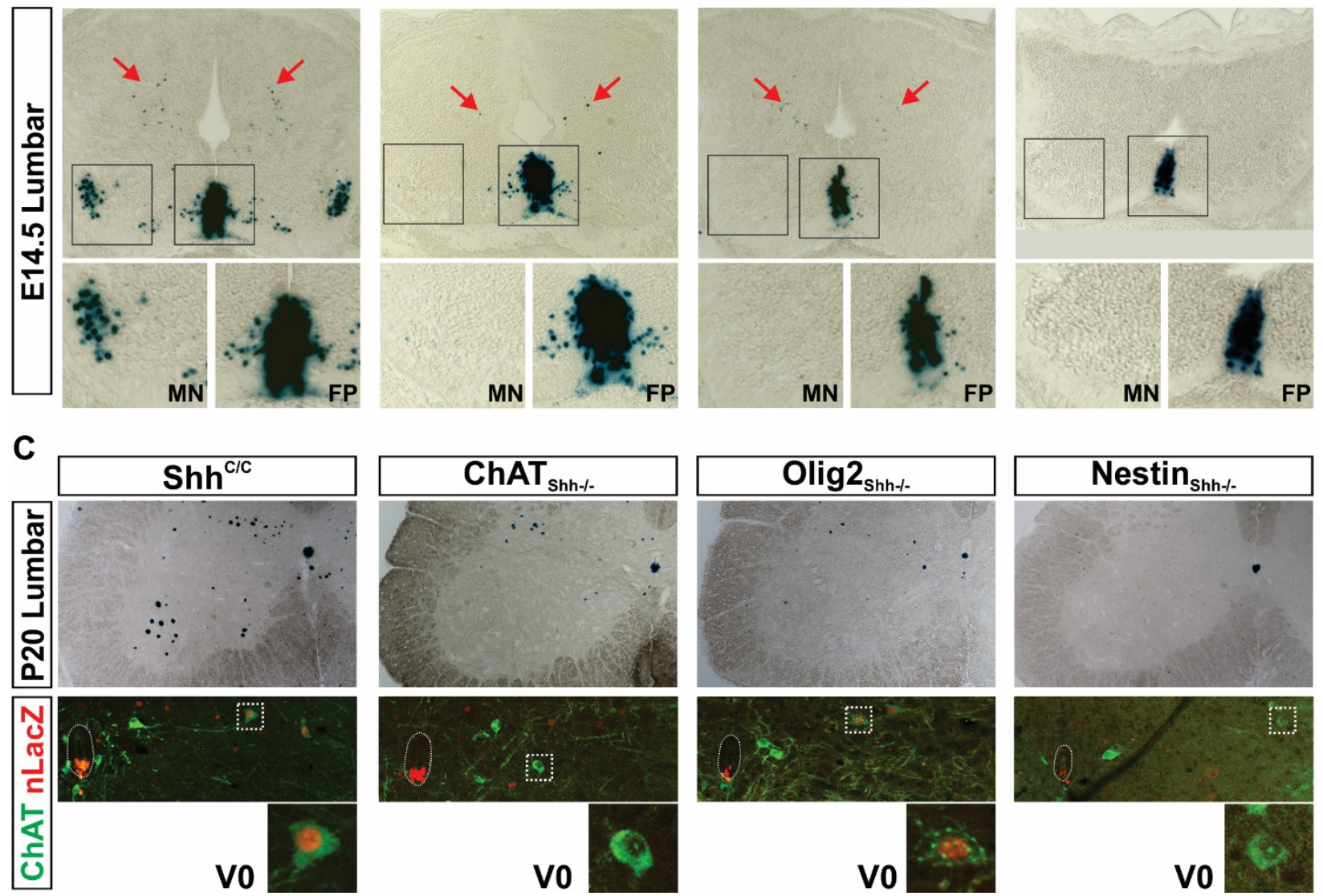

Fig. S2. Ablation of Shh from MFP and VZD sources

(A and B) X-gal staining revealing ablation of Shh at lumbar spinal cord at (A) E13.5, and (B) E14.5. Arrows in B point to a dorsal Shh source located near the ventricular zone appearing at E14.5.

(C) X-gal staining of P20 spinal cords revealing loss of Shh expression from MNs and Vo cholinergic interneurons in ChAT Shh ${ }^{-1}$, MNs and descendants of neurons ventral to the Olig2 domain in Olig2 $\mathrm{Shn}^{-1-}$, and all neuronal sources in Nestinshn ${ }^{-1}$. 


\section{AnkG}

\section{E10.5 $\quad$ E12.5}
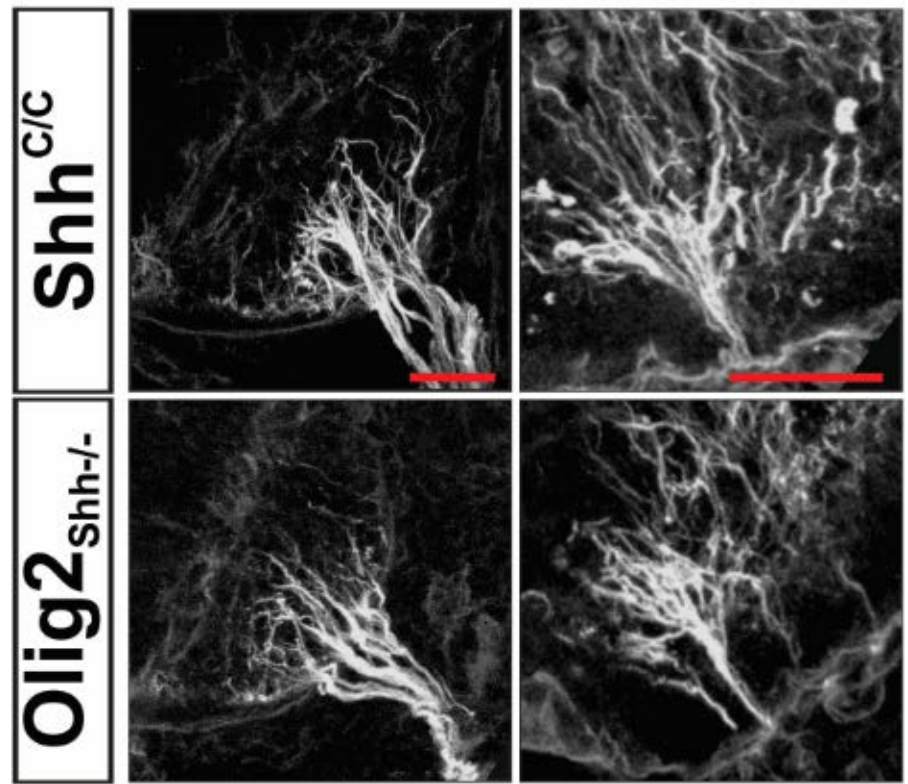

Fig. S3. AnkG staining at E10.5 and E12.5 revealing correct $\mathrm{MN}$ axon fasciculation and exit from ventral horns in Olig2 $\mathrm{Shh}^{-{ }^{-1}}$. 
E14.5

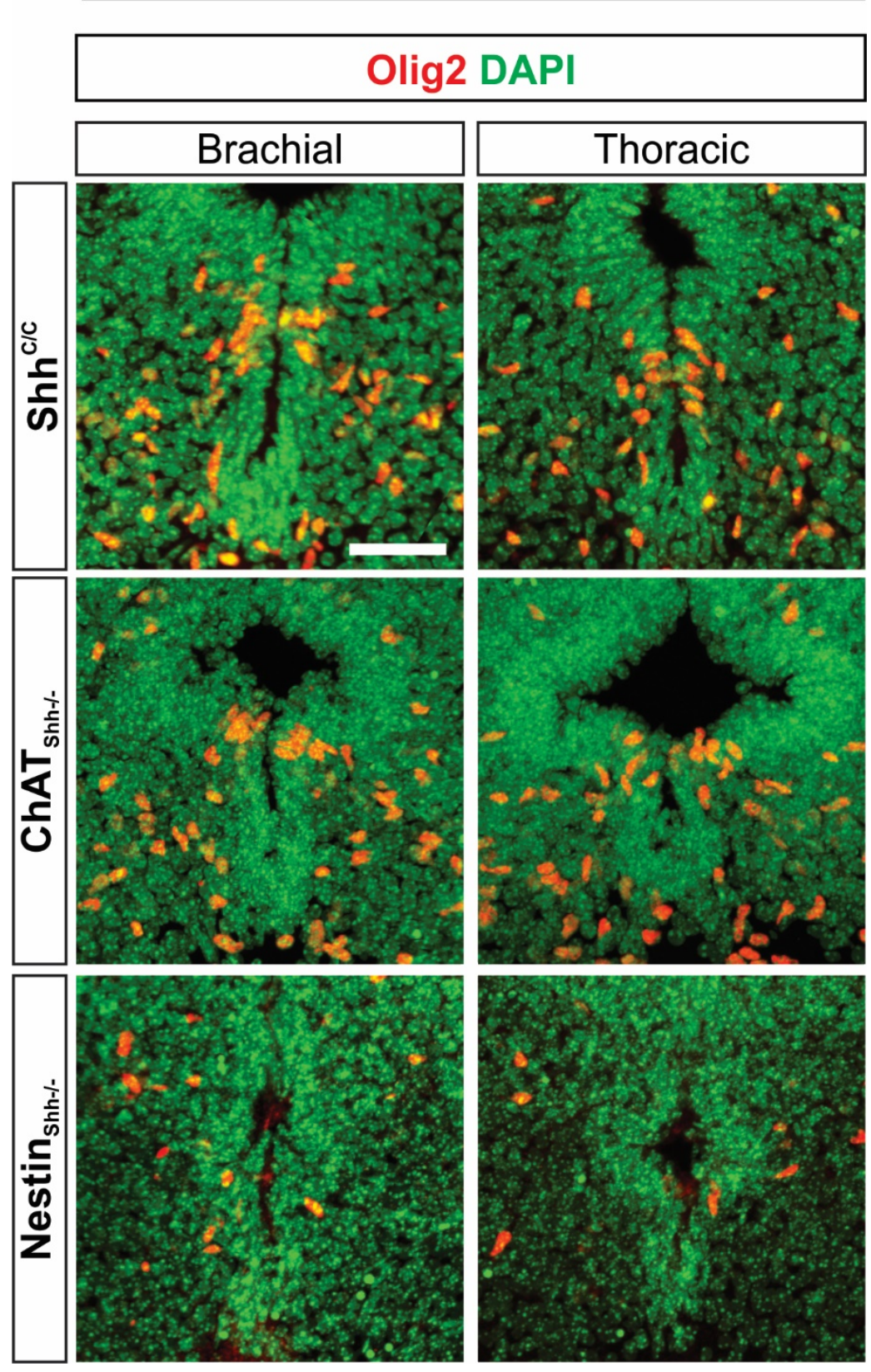

Fig. S4. Immunostaining of Olig2 and DAPI on brachial and thoracic segments reveals the continued depletion of Olig2 cells from the $\mathrm{pMN}$ of Nestinshh ${ }^{-1-}$ but not $\mathrm{ChAT}_{\mathrm{Shh}^{-1-}}$ at E14.5. 


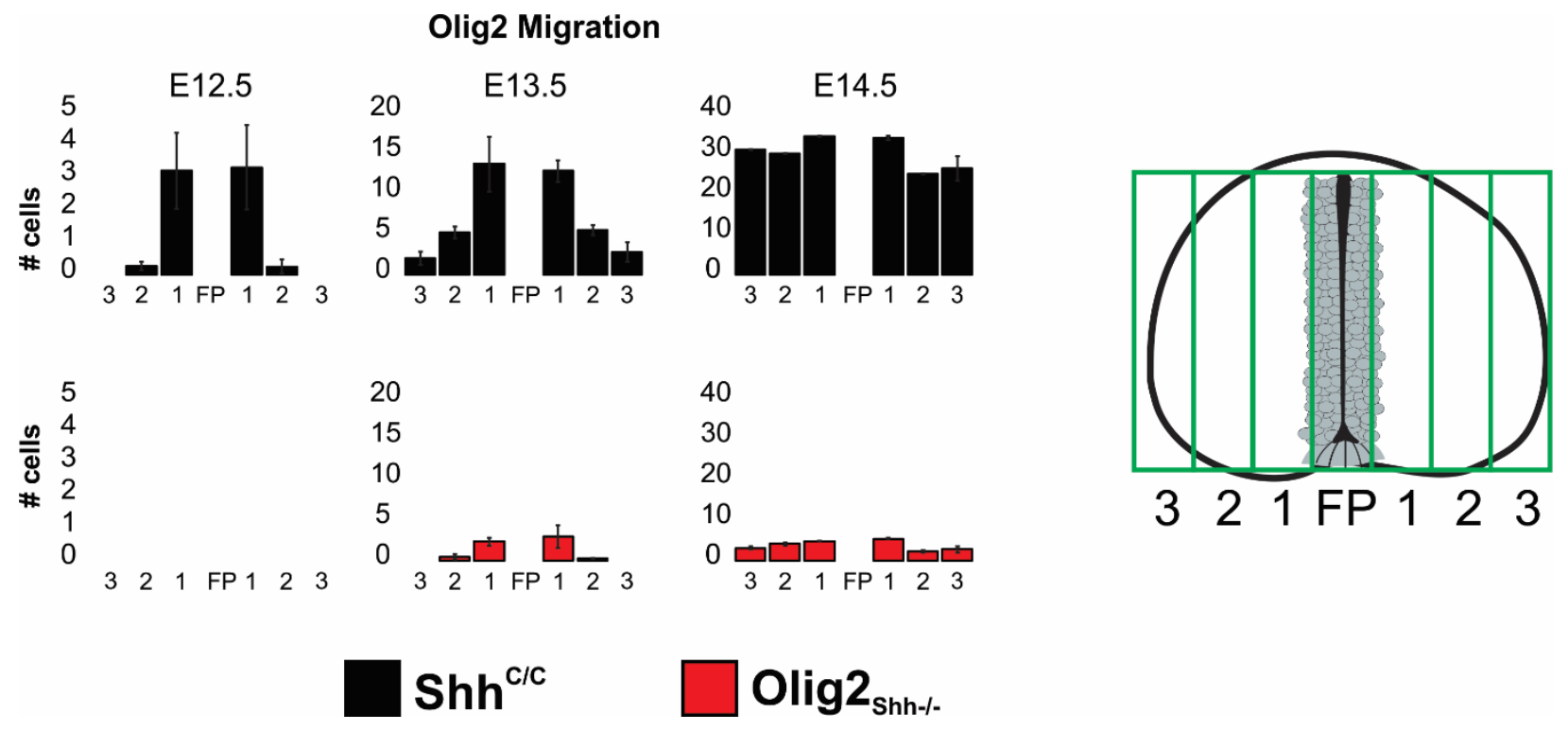

Fig. S5. Analysis of migrating Olig2 cell dispersion in Olig2 $\mathrm{shh}^{-1-}$ mutant and control embryos.

Lumbar spinal cord sections from E12.5-E14.5 were binned into 6 zones excluding the ventricular zone, and numbers of Olig2 cells in each zone were quantified. Means \pm SEM are shown. Shh ${ }^{\mathrm{ClC}}(\mathrm{n}=3-4$ embryos $)$, Olig2 $\mathrm{Shh}^{-1-}(\mathrm{n}=3$ embryos $)$. 

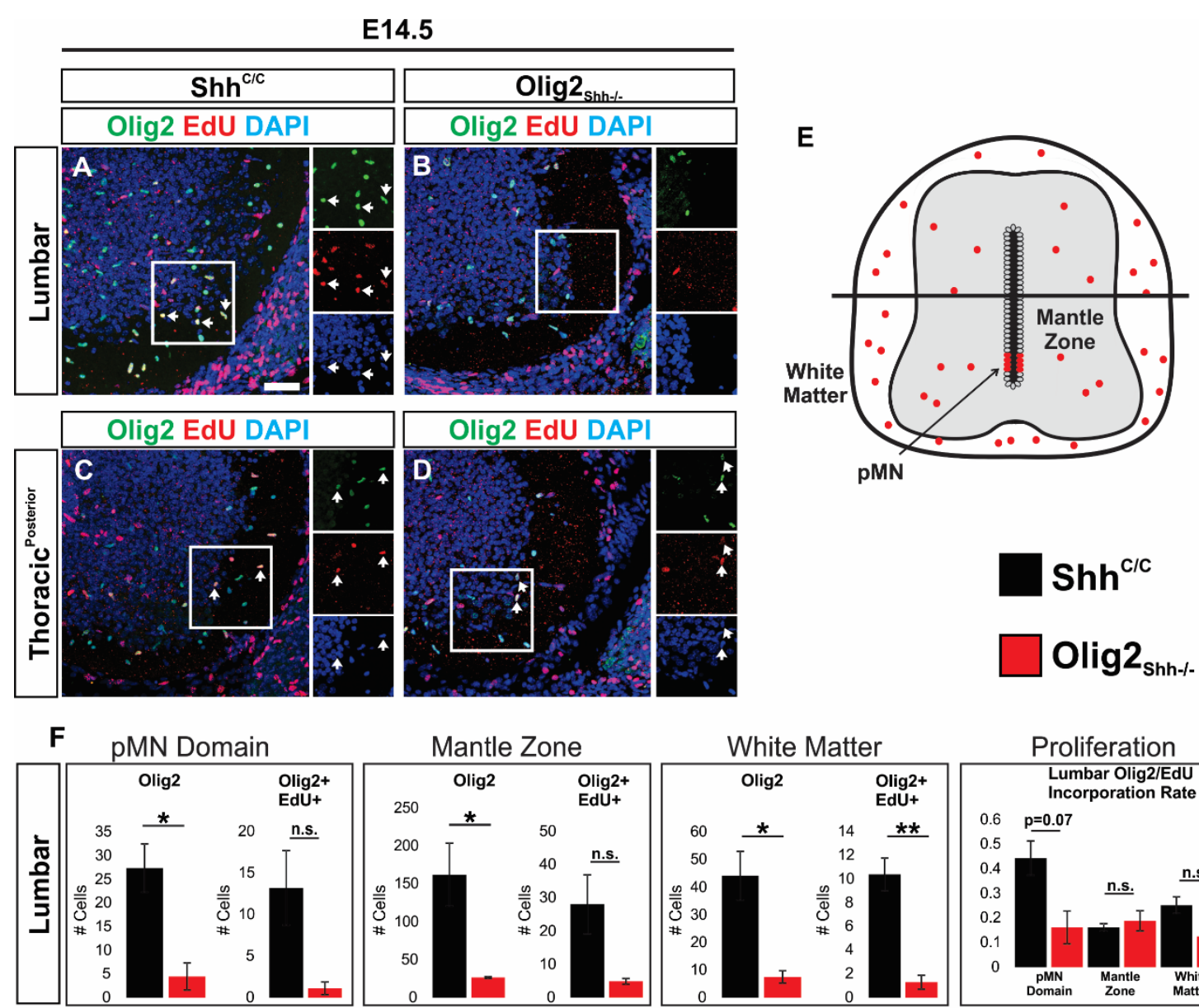

G
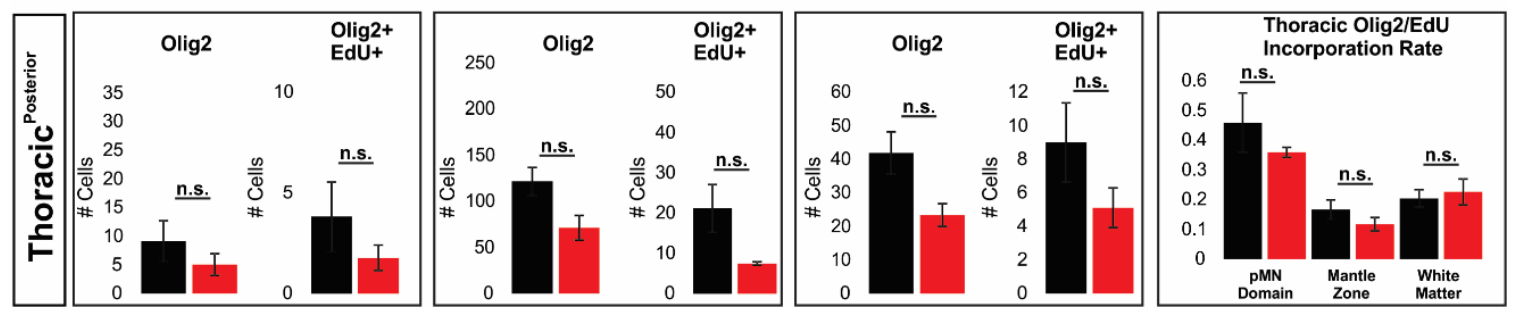

Fig. S6. OPCs are reduced and do not increase proliferation rate.

(A-D) Immunostaining on E14.5 sections for Olig2, EdU, and DAPI at (A and B) lumbar and (C and D) posterior thoracic. Arrows indicate co-expression of Olig2 and EdU.

(E) Schematic depicting areas analyzed.

( $F$ and G) 24hr pulse chase with a single EdU injection to label proliferating Olig2 cells. Total Olig2 cells and Olig2+ Edu+ double positive cells are reduced in the pMN, mantle zone, and white matter at both $(\mathbf{F})$ lumbar and $(\mathbf{G})$ posterior thoracic segments in Olig2 $\mathrm{Shh}^{-1-}$ compared to control. Shh ${ }^{\mathrm{ClC}}$ ( $\mathrm{n}=3$ embryos), Olig2 $\mathrm{Shh}^{-1 /}(\mathrm{n}=3$ embryos). Means \pm SEM are shown. Data were analyzed by Student's t test. $* \mathrm{p}<0.05, * * \mathrm{p}<0.01$. Scale bars, $50 \mu \mathrm{m}$. 